This item was submitted to Loughborough's Research Repository by the author.

Items in Figshare are protected by copyright, with all rights reserved, unless otherwise indicated.

\title{
Poly(4-vinylaniline)/polyaniline bilayer functionalized bacterial cellulose membranes as bioelectronics interfaces
}

PLEASE CITE THE PUBLISHED VERSION

https://doi.org/10.1016/j.carbpol.2018.10.017

\section{PUBLISHER}

(C) Elsevier

\section{VERSION}

AM (Accepted Manuscript)

\section{PUBLISHER STATEMENT}

This paper was accepted for publication in the journal Carbohydrate Polymers and the definitive published version is available at https://doi.org/10.1016/j.carbpol.2018.10.017

\section{LICENCE}

CC BY-NC-ND 4.0

\section{REPOSITORY RECORD}

Rebelo, Ana M. Rodrigues, Yang Liu, Changqing Liu, Karl-Herbert Schafer, Monika Saumer, and Guang Yang. 2019. "Poly(4-vinylaniline)/polyaniline Bilayer Functionalized Bacterial Cellulose Membranes as Bioelectronics Interfaces". figshare. https://hdl.handle.net/2134/36279. 


\section{Accepted Manuscript}

Title: Poly(4-vinylaniline)/polyaniline bilayer functionalized bacterial cellulose membranes as bioelectronics interfaces

Authors: Ana Rebelo, Yang Liu, Changqing Liu, Karl-Herbert Schäfer, Monika Saumer, Guang Yang

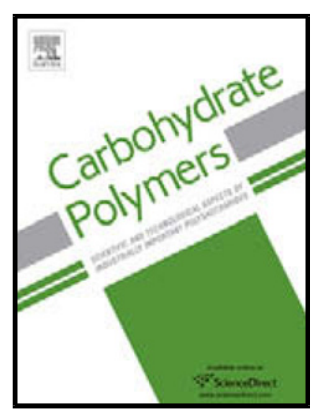

PII: S0144-8617(18)31193-7

DOI: https://doi.org/10.1016/j.carbpol.2018.10.017

Reference: CARP 14149

To appear in:

Received date: $\quad 6-8-2018$

Revised date: $\quad$ 5-10-2018

Accepted date: $\quad$ 6-10-2018

Please cite this article as: Rebelo A, Liu Y, Liu C, Schäfer K-Herbert, Saumer M, Yang G, Poly(4-vinylaniline)/polyaniline bilayer functionalized bacterial cellulose membranes as bioelectronics interfaces, Carbohydrate Polymers (2018), https://doi.org/10.1016/j.carbpol.2018.10.017

This is a PDF file of an unedited manuscript that has been accepted for publication. As a service to our customers we are providing this early version of the manuscript. The manuscript will undergo copyediting, typesetting, and review of the resulting proof before it is published in its final form. Please note that during the production process errors may be discovered which could affect the content, and all legal disclaimers that apply to the journal pertain. 


\section{Poly(4-vinylaniline)/polyaniline bilayer functionalized bacterial cellulose membranes as bioelectronics interfaces}

Ana Rebelo ${ }^{a, b}$, Yang Liu ${ }^{a, b}$, Changqing Liu ${ }^{a} *$, Karl-Herbert Schäfer ${ }^{c}$, Monika Saumer ${ }^{c}$, Guang Yang $^{d}$

${ }^{\mathrm{a}}$ Wolfson School of Mechanical, Electrical and Manufacturing Engineering, Loughborough University, Loughborough, LE11 3TU, UK

${ }^{\mathrm{b}}$ Centre for Biological Engineering, Holywell Park, Loughborough University, Loughborough, LE11 3TU, UK

${ }^{\mathrm{c}}$ Department of Applied Sciences, University of Applied Sciences Kaiserslautern, Zweibrücken, 66482, Germany

${ }^{\mathrm{d}}$ Department of Biomedical Engineering, College of Life Science and Technology, Huazhong University of Science and Technology, Wuhan, 1037, PR China

* Corresponding Author

E-mail: c.liu@1boro.ac.uk. Phone: +44 (0)1509227681

Graphical abstract 
PVAN/PANI bilayer functionalized BC

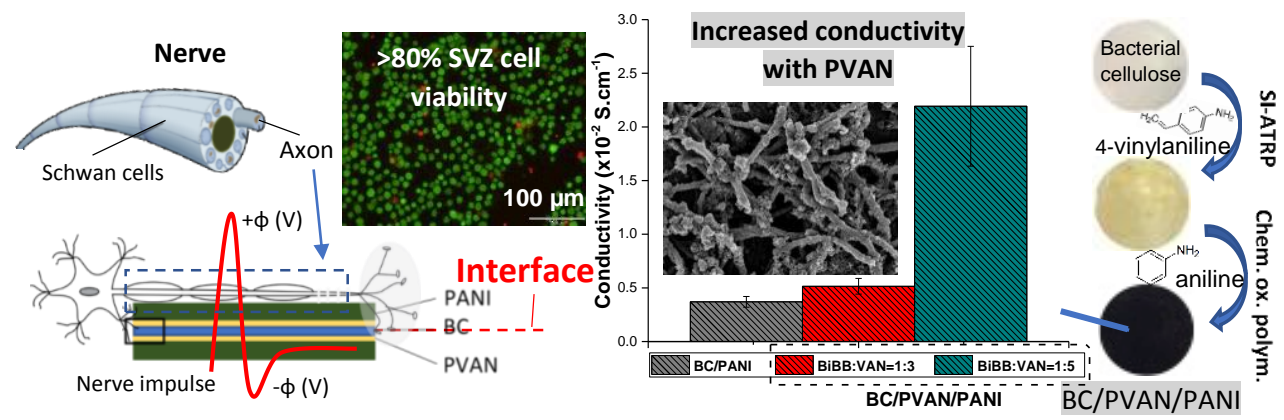

Highlights:

- $\quad$ ATRP combined with COP process to modify PANI coated BC with PVAN interlayer.

- Formation of an intact PVAN/PANI bilayer of $\sim 2 \mu \mathrm{m}$ on the BC membrane.

- Enhanced electrical conductivity of BC/PVAN/PANI with PVAN grafting.

- Confirmed SVZ cell viability of PVAN/PANI functionalised BC membrane.

- Demonstration of BC/PVAN/PANI for construction of potential bioelectronic interfaces.

\begin{abstract}
Bacterial cellulose (BC) fibers are chemically functionalized with poly(4-vinylaniline) (PVAN) interlayer for further enhancement of electrical conductivity and cell viability of polyaniline (PANI) coated BC nanocomposites. PVAN is found to have promoted the formation of a uniform PANI layer with nanofiber- and nanorod-like supramolecular structures, as an overall augmentation of PANI yield. Compositional and microstructural analysis indicates a PVAN/PANI bilayer of approximately $2 \mu \mathrm{m}$ formed on BC. The solid-state electrical conductivity of such synthesized BC nanocomposites can be as high as $(4.5 \pm 1.7) \times 10^{-2}{\mathrm{~S} . \mathrm{cm}^{-1}}^{-1}$ subject to the amounts of PVAN chemically embraced. BC/PVAN/PANI nanocomposites are
\end{abstract}


confirmed to be thermally stable up to $225^{\circ} \mathrm{C}$, and no signs of cytotoxicity for SVZ neural stem cells are detected, with cell viability up to $90 \%$ on BC/PVAN/PANI membranes. We envisage these new electrically conductive BC/PVAN/PANI nanocomposites can potentially enable various biomedical applications, such as for the fabrication of bioelectronic interfaces and biosensors.

Keywords: Bacterial cellulose, functionalization, conducting composites, bioelectronic interfaces

\section{Introduction}

Bioelectronic devices act as biologic-electronics interfaces, such as neural interfaces, to detect and record electrical signals from a biosystem and/or artificially stimulate it (Guz et al., 2016; Spearman et al., 2018). The fabrication of such bioelectronic interfaces requires the uses of biocompatible materials with reasonable electrical conductivity, long-term mechanical support and efficient bidirectional transducing paths between an electrical equipment and a biological structure. Despite the significant endeavor to enhance the electrical conductivity of the materials used for assembly of such devices, the complex aspects of biocompatibility have so far been given insufficient attention (Spearman et al., 2018).

Bacterial cellulose $(\mathrm{BC})$ with its unique 3D nanofibrillar network and high water holding capacity (up to $98 \%$ ), was approved by U.S. Food and Drug Administration (FDA) as a biocompatible material for various biomedical applications, including wound dressings and artificial vessels (Abeer, Mohd Amin, \& Martin, 2014). Desirable mechanical properties of BC can be further tailored through variations in the water content (H.-J. Lee, Chung, Kwon, Kim, \& Tze, 2012; R. Rebelo et al., 2018). However, electrically functionalization is required for a wide 
range of biomedical applications such as, electrostimulated drug delivery systems (Ge et al., 2010; J. Li et al., 2017), biosensors (J. Fu et al., 2015; Jasim, Ullah, Shi, Lin, \& Yang, 2017), bioelectronics (Kim, Jeon, Kim, Kee, \& Oh, 2015; Shi, Li, Chen, Han, \& Yang, 2014; Ul-Islam, Khattak, Ullah, Khan, \& Park, 2014) and tissue regeneration (Shi et al., 2012). The porous BC matrix can accommodate electroactive moieties, such as carbon nanotubes (CNTs), graphene, metal nanoparticles, and intrinsic electroconductive polymers (ICPs) (Shi et al., 2014). Among these, ICPs, also named as conjugated polymers can permit a fine control over electrical and optical properties, owing to the delocalization of electrons in a continuously overlapped S-orbital along the polymer backbone (Kaur, Adhikari, Cass, Bown, \& Gunatillake, 2015; Y. Li \& Li, 2015). As one of the most studied ICPs, polyaniline (PANI) is easily synthesized and possesses a high environmental stability, with simple doping/dedoping chemistry (Huanhuan Wang et al., 2012). On account of this finding, it has been invariably utilized as electrical conductors (Yan, Sada, \& Toshima, 2002), batteries (L. Hu, Ren, Yang, \& Xu, 2014), sensors (Langer et al., 2004), actuators (Smela, Lu, \& Mattes, 2005), electromagnetic shielding (Gupta, Singh, Mathur, \& Dhakate, 2014), antistatic coatings (Soto-Oviedo, Araújo, Faez, Rezende, \& De Paoli, 2006), corrosion protection (Mirmohseni \& Oladegaragoze, 2000; Yuan et al., 2012), and electro-optic and electrochromic devices (Shi et al., 2012). However, pure PANI is typically obtained as an intractable powder that largely hinders its uses in order to fully exploit its functional potentials (Valentová \& Stejskal, 2010). This barrier can be potentially overcome by incorporating PANI in a BC nanofibrils matrix through grafting or surface coating technologies (W. Hu, Chen, Yang, Liu, \& Wang, 2011). The preparation procedure adopted is of the highest importance to enhance the electronic performance of conducting devices (Andrei, Bethke, Madzharova, Beeg, et al., 2017; Andrei, Bethke, Madzharova, Bronneberg, et al., 2017; Bethke et al., 2018; Casado, 
Aranguren, \& Marcovich, 2014; E. J. Jelmy, Ramakrishnan, Devanathan, Rangarajan, \& Kothurkar, 2013).

BC/PANI nanocomposites have been successfully synthesized by in situ oxidative polymerization of aniline directly onto BC, via either chemical or electrochemical methods, showing promising results for biomedical applications that demand suitable electroactive characteristics and flexibility in material's handling, in particular for neural interfaces (W. Hu et al., 2011; H.-J. Lee et al., 2012; Müller et al., 2012; Shi et al., 2012, 2014; Huanhuan Wang et al., 2012). In this work, we introduce an intermediate polymeric layer of poly(4-vinylaniline) (PVAN) prior to the PANI coating on BC nanofibrils, as schematically shown in Figure 1. PVAN has been previously exploited as a precursor of aniline polymerization in anticorrosive metal coatings (Yuan et al., 2012), surface modification of poly(tetrafluoroethylene) (L. Y. Ji, Kang, Neoh, \& Tan, 1999) and to assist in the production of conductive hollow nanospheres (G. D. Fu, Zhao, Sun, Kang, \& Neoh, 2007). It can be grafted by means of atom transfer radical polymerization (ATRP) (Figure 1b), which can facilitate a strong adhesion for PANI to attach onto different substrates at the expenses of the free aniline pending moieties, as such it can promote higher concentrations of immobilized PANI (Figure 1c) (G. D. Fu et al., 2007; L. Y. Ji et al., 1999). Owing to the hydroxyl richness, BC is susceptible for surface modification with PVAN by grafting-from ATRP (Lizundia, Meaurio, \& Vilas, 2016) to subsequently embrace PANI by chemical oxidative polymerization (COP) (Figure 1b). This PVAN/PANI bilayer is expected to strongly tether to $\mathrm{BC}$ thus enhancing the functional performance such as electrical properties. Compared to the commonly synthesized BC/PANI composites (Jasim et al., 2017; B.H. Lee, Kim, \& Yang, 2012), PVAN-treated BC/PANI (BC/PVAN/PANI) could have PANI much strongly grafted while improving the grafting yield and promoting PANI particles 
distribution on $\mathrm{BC}$ fibers with improved doping access. This may lead to a more consistent and cohesive electrical coating, along with an increase of the overall electrical conductivity. Also, we anticipate the potential change of morphology of PANI due to the use of PVAN interlayer could be favorable to the cell growth, thus further enhancing the biocompatibility.

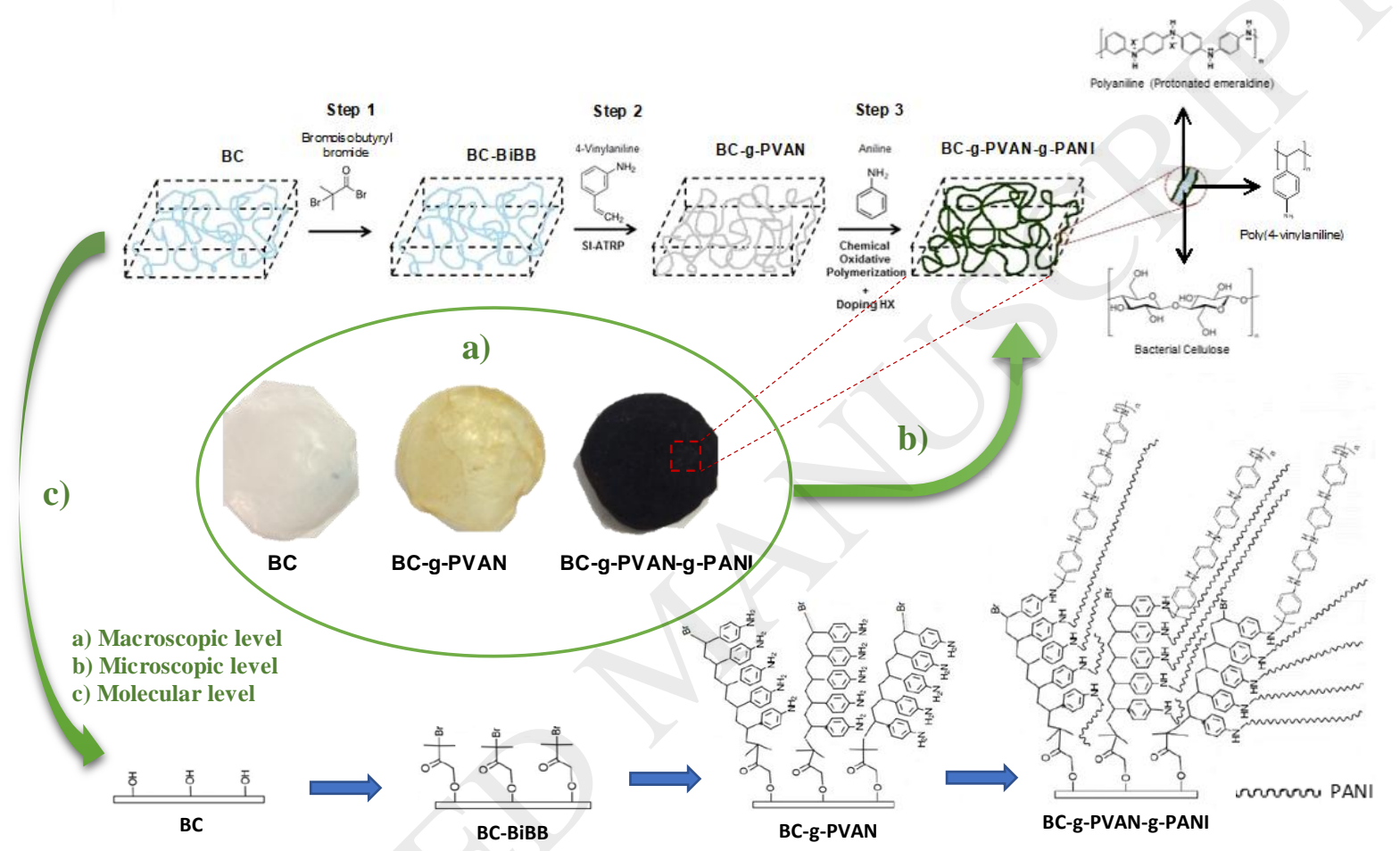

Figure 1. Schematic synthesis of BC/PVAN/PANI nanocomposite membranes at a)

macroscopic, b) microscopic and c) molecular levels. Step 1: Initiator (BiBB) immobilization onto BC. Step 2: Surface-initiated atom transfer radical polymerization of 4-vinylaniline onto BC. Step 3: Chemical oxidative polymerization of aniline on BC-graft-PVAN (or BC/PVAN) in the presence of $\mathrm{HCl}$ as doping agent, to form BC-graft-PVAN-graft-PANI (or BC/PVAN/PANI).

In this study, we have optimized our newly developed BC/PANI synthesis process with PVAN interlayer, followed by detailed characterization through electroconductive measurements (4probe method), morphology (SEM/HRTEM-EDS), chemical structure (XPS) and thermal 
analysis (TGA). It is our primary concern to understand the properties offered by the newly modified BC-nanocomposites with PVAN interlayer. In addition, the cell viability was examined with neural stem cells for possible neural interfaces in the future. The results obtained suggests prospective for future developments, and this has been demonstrated in terms of construction of cellulosic-based bioelectronic devices for nervous system, which may be extended to a wised range of possible application with the conductive PVAN/PANI coatings.

\section{Experimental section}

\subsection{BC membranes synthesis}

BC membranes were produced from fermentation of Gluconacetobacter hansenii (ATCC $\mathbb{R}$ 53582TM), harvested in 6-well plates $(3.5 \mathrm{~cm})$ and kept in a sterile environment under static conditions for 4 days. The culture medium was prepared in pure water containing 6.8 g.L $\mathrm{L}^{-1}$ disodium hydrogen phosphate dodecahydrate, 5 g.L $\mathrm{L}^{-1}$ peptone, 5 g.L $\mathrm{L}^{-1}$ yeast extract, 1.5 g.L $\mathrm{L}^{-1}$ citric acid, 20 g.L.-1 glucose. The obtained BC membranes were soaked with pure water for 2-3 days, prior to boiling with $4 \mathrm{~g} . \mathrm{L}^{-1}$ sodium hydroxide solution for $40 \mathrm{~min}$ to remove medium and any adsorbed bacteria. The as-prepared BC hydrogels $3.2 \pm 0.5 \mathrm{~mm}$ thick were dried in an oven under the ambient conditions for overnight at $60{ }^{\circ} \mathrm{C}$.

\subsection{Surface-initiated ATRP of 4-vinylaniline}

2-Bromoisobutyryl bromide (BiBB) was immobilized onto the hydroxyl-rich BC substrates to provide the initiating sites for ATRP polymerization of 4-VAN. The oven-dried BC membranes 
were mixed with 4-dimethylaminopyridine (DMAP, Sigma Aldrich), dry-dimethylformamide (dry-DMF, Fisher Scientific) and triethylamine (TEA, Sigma Aldrich) under stirring, to which BiBB (Sigma Aldrich) was added dropwise in an ice-bath. The feeding molar ratio used was BiBB:TEA:DMAP=1:2:2. The reaction was kept under inert atmosphere with protective argon gas and left at room temperature for 24 hours . The resultant BC-initiator membranes were then soaked in dimethylformamide (DMF, Sigma Aldrich) for 2 days as purification step, prior to PVAN grafting. ATRP was carried out with dissolution of VAN monomer (97 \% Sigma Aldrich) in DMF, together with copper (II) chloride $\left(\mathrm{CuCl}_{2}\right.$, Sigma Aldrich) and $\mathrm{N}, \mathrm{N}, \mathrm{N}^{\prime}, \mathrm{N}^{\prime \prime}, \mathrm{N}^{\prime \prime}-$ pentamethyldiethylenetriamine (PMEDTA, Fisher Scientific) under argon atmosphere, before injecting ascorbic acid (ASCA, Sigma Aldrich) dropwise. BC-initiator membranes were later inserted to the reaction. ATRP was left running for 24 hours at room temperature, after which the grafted $\mathrm{BC}$ (referred to as $\mathrm{BC}-\mathrm{g}-\mathrm{PVAN}$ or $\mathrm{BC} / \mathrm{PVAN}$ ) was thoroughly washed with DMF and left in an excess amount of DMF overnight to ensure the removal of any physically adsorbed PVAN homopolymer. The molar ratio used for the reaction were $\mathrm{CuCl}_{2}: \mathrm{PMDETA} A \mathrm{ASCA}: \mathrm{VAN}=1: 2: 5: 500$ and two different VAN monomer ratios (BC:VAN=1:3 and 1:5) were used in this study.

\subsection{Aniline polymerization}

The grafted conductive PANI layer on BC/PVAN composites (referred to as BC-g-PVAN-gPANI or BC/PVAN/PANI) was prepared via chemical oxidative polymerization of aniline on BC-g-PVAN. BC/PVAN was first dipped into a $10 \mathrm{~mL}$ aqueous solution of $1 \mathrm{M}$ hydrochloric acid $(\mathrm{HCl}, 32 \%)$ containing $0.25 \mathrm{M}$ of ammonium persulfate $\left(\left(\mathrm{NH}_{4}\right)_{2} \mathrm{~S}_{2} \mathrm{O}_{8}\right.$, APS, Sigma Aldrich). $0.20 \mathrm{M}$ of aniline (ANI, Sigma Aldrich) was added dropwise afterwards, and the 
reaction was left for 6 hours in an ice-bath (at 0-5 $\left.{ }^{\circ} \mathrm{C}\right)$. These were designated as standard conditions. Purification of the ready-grafted BC/PVAN/PANI membranes was done with thorough washes with ethyl alcohol (ETA, 100\% Sigma Aldrich) and distilled water, and ovendried overnight at $60{ }^{\circ} \mathrm{C}$. The thickness of dried samples was measured between $0.3-0.5 \mathrm{~mm}$. Adjustments to aniline polymerization parameters, including acid concentration $(0.5 \mathrm{M}, 1 \mathrm{M})$, molar ratio of oxidant to monomer $(1: 1,1: 1.25,1: 1.5)$, monomer concentration $(0.2 \mathrm{M}, 0.5 \mathrm{M}$, $0.7 \mathrm{M}$ ) and polymerization time (3 hours, 6 hours, 18 hours), were performed to investigate the effects of each individual parameter. BC/PANI membranes were also prepared from pre-oven dried BC membranes under standard COP conditions for comparison in terms of morphological and electrical characteristics of the nanocomposites.

\subsection{Material characterization}

The morphology of untreated and grafted BC membranes was analyzed using scanning electron microscopy (SEM) and transmission electron microscopy (TEM). The samples were assembled on carbon tape and sputtered with $0.1 \mathrm{~mm}$ thick gold/palladium for 60 seconds with a rotatory-pumped coating system (Q150R S, Quorum Technologies, UK) prior to SEM observation (GeminiSEM, Zeiss). To acquire spatially resolved microstructural and compositional information of the membranes, conventional and high resolution TEM (C-/HRTEM) were performed using a FEI Tecnai F20 operating at $200 \mathrm{kV}$. The EDX elemental maps were acquired in the scanning TEM (STEM) mode, using long dwell time to minimize beam drift during data collection. The TEM samples were attached to copper grids using a standard lift-out method on a FEI Nova SEM/FIB dual-beam microscope, fitted with a liquid Ga ion source and operating at $30 \mathrm{kV}$ accelerating voltage. Ion-beam Pt was applied on site to minimize any ion 
milling artefact. X-ray photoelectron spectroscopy (XPS) was performed on BC, BC/PVAN and BC/PVAN/PANI membrane samples using a spectrometer from Thermo ScientificTM equipped with an Al K-AlphaTM source. Survey and selective high-resolution spectra were collected using 1 and $0.1 \mathrm{eV}$ pass energy. Samples were mounted on double sided adhesive tape and the analyzer chamber was degasified, keeping the pressure at as low as 108 Torr. Spectral analysis was carried out using the Thermo Scientific ${ }^{\mathrm{TM}}$ Avantage Data System for quantification and peak fitting. Quantification was based on peak areas calculated from the high-resolution spectra. All spectra shown were charge-balanced with dual beam source (source gun A: X-Ray004 $150 \mu \mathrm{m}$ FG ON $(150 \mu \mathrm{m})$ and source gun B: shutdown $(0 \mu \mathrm{m}))$. Thermal gravimetric curves were obtained for BC, BC/PVAN and BC/PVAN/PANI samples with a Thermogravimetric Analyzer (TGA) SDT Q600 V20.9 Build 20 from TA Instruments. Samples were heated in open alumina pans from 30 to $800{ }^{\circ} \mathrm{C}$, under a nitrogen atmosphere, at a heating rate of $10^{\circ} \mathrm{C} \cdot \mathrm{min}^{-1}$.

\subsection{Electrical measurements}

The sheet resistance (R) of 5 samples was measured on both sides of the membranes at three different sites with a Jandel four-point probes (Model HM20) at room temperature in dry state. As the thickness ( $(t)$ of the samples were much smaller than the probe spacing (S) $(t / S<<5)$, the electrical conductivity $\left({\left.\mathrm{S} . \mathrm{cm}^{-1}\right)}^{-}\right.$was derived from the reciprocal of the bulk resistivity $(\rho)$ according to the following equation (1) (Alonso et al., 2018):

$\sigma=\frac{1}{\rho}=\frac{\ln 2}{\pi} \frac{1}{t R}$.

\subsection{Cell isolation and cytocompatibility}

Cells exposed to a cytotoxic compound follow different response mechanisms, that can be either lethal or sublethal. When lethal, cells may undergo necrosis in which cells lose 
membrane integrity and die rapidly, or may follow auto-programmed cell death, such as apoptosis or autophagy; when sublethal, cells may stop actively growing and dividing (a decrease in cell proliferation). Any of these responses can be measure with cytotoxic assays, including cell viability assays.

To investigate whether the synthesized BC nanocomposites, especially BC/PVAN/PANI membranes, generates cytotoxic response, cell viability assay was performed on primary SVZ cells that were isolated from subventricular zones of 1-5 days old postnatal BALB/c mice (P1P5), following German local regulations for animal welfare. After appropriate cell purification and digestion procedures, cells were grown in proliferation medium consisting of DMEM/F12 GlutaMAX supplemented with 1\% Penicillin/Streptomycin (10,000 u Penicillin, $10 \mathrm{mg} \cdot \mathrm{mL}^{-1}$ Streptomycin), $1 \%$ bovine serum albumin (BSA, 35\% in PBS), 2\% neural cell culture supplement $\beta$-27 (without retinoic acid), $\beta$ - mercaptoethanol $(50 \mathrm{mM}), 0.2 \%$ recombinant human fibroblast growth factor (rhßFGF, $10 \mu \mathrm{g} \cdot \mathrm{mL}^{-1}$ ) and $0.1 \%$ recombinant human epidermal growth factor (rhEGF, $10 \mu \mathrm{g} \cdot \mathrm{mL}^{-1}$ ). The culture was kept in the incubator for 5 days at $37^{\circ} \mathrm{C}$ and $5 \% \mathrm{CO}_{2}$ atmosphere with medium replenished every 2 days, followed by dissociation. SVZ cells harvested were further incubated with BC scaffolds in 24 -well plates at $2 \times 10^{4}$ cells per well and kept for 7 days in proliferation medium under the atmospheric conditions described above. Cell suspensions were collected at day 7 and live/dead assay was performed to verify cell cytotoxicity. The staining solution was prepared in PBS containing $1 \%$ calcein acetoxymethyl ester (calcein-AM) and 1\% propidium iodine (PI). $200 \mu 1$ of dual fluorescence calcein AM/PI solution were added into each well and incubated for 20 min at $37{ }^{\circ} \mathrm{C}$. Four images per well were taken using a fluorescence microscope (Olympus, IX71, Japan), which were used to calculate the average number of live and dead cells on each well. Live cells were 
stained green with fluorescent calcein-AM to indicate intracellular esterase activity and dead cells were stained red with fluorescent PI to indicate loss of plasma membrane integrity. Cell viability was calculated for each condition based on the average of three replicates using the following equation:

Cell viability $(\%)=\frac{\text { live cells }}{\text { total number of cells }} \times 100 \%$,

where the total number of cells correspond to the sum of live and dead cells.

Student's t-test and one-way ANOVA were performed accordingly to discern about statistical differences between the conditions at confidence level of $95 \%$ ( $\mathrm{p}$-value $<0.05)$.

\section{Results and discussion}

\subsection{Compositional and microstructural characterization of PVAN/PANI functionalized BC}

As schematically shown in Figure 1, synthesis of BC/PVAN/PANI nanocomposite membranes has been achieved through the $\mathrm{BC}$ grafting chemical processes. The SEM and HRTEM morphology of these as-prepared nanocomposites (Figure 2) indicates that PANI functional coatings can cause immediate changes of texture and roughness to the original $\mathrm{BC}$ substrate as it has been observed elsewhere (Bandeira, van Drunen, Garcia, \& Tremiliosi-Filho, 2017). Accordingly, the type of PANI supramolecular structures (Figure 2d-f) is closely correlated with the polymerization conditions and the adopted synthetic procedure. Under highly acidic media with strong oxidants, PANI usually exhibits a granular morphology as observed in both BC/PANI and BC/PVAN/PANI membranes with BiBB:VAN=1:3 monomer content (Figure 2d,e), which has been reported for BC/PANI grafted membranes (Huanhuan Wang et al., 2012), as also present in Figure 2d. This is regarded as the result of random aggregation of high 
concentrations of aniline nucleates, which were produced during the short induction period (I. Sapurina \& Stejskal, 2008). These hydrophobic nucleates are continuously formed and agglomerate together while PANI chains grow. Under magnetic stirring, heterogeneous nucleation takes place and new initiating sites appear on the surface of preformed particles, leading to a granular morphology (Yu Sapurina \& Stejskal, 2012). However, it has been found in the present study that a lower ratio BiBB to VAN can cause the formation of both granules and nanofibers, providing also a more uniform PANI coverage on the BC nanofibers (Figure 2f).

PVAN on BC in such instance acts as a soft template that can induce preferential PANI growth (Chiou, Lee, \& Arthur, 2007), while stabilizing interactions between phenazine-containing structures probably owing to its surfactant properties (i.e. primary amine surfactant) (Kuczynska et al., 2010). Under such conditions, homogeneous nucleation may take place with the suppression of secondary nucleates, which has been observed as a key factor for synthesis of this type of supramolecular structure (D. Li \& Kaner, 2007). Denser PVAN brushes implies more initiating sites for nucleation that may induce the continuous growth of PANI nanofibers in their vicinity (Tian et al., 2014). Thus, different supramolecular PANI structures can be obtained subject to different PVAN grafting degrees. 

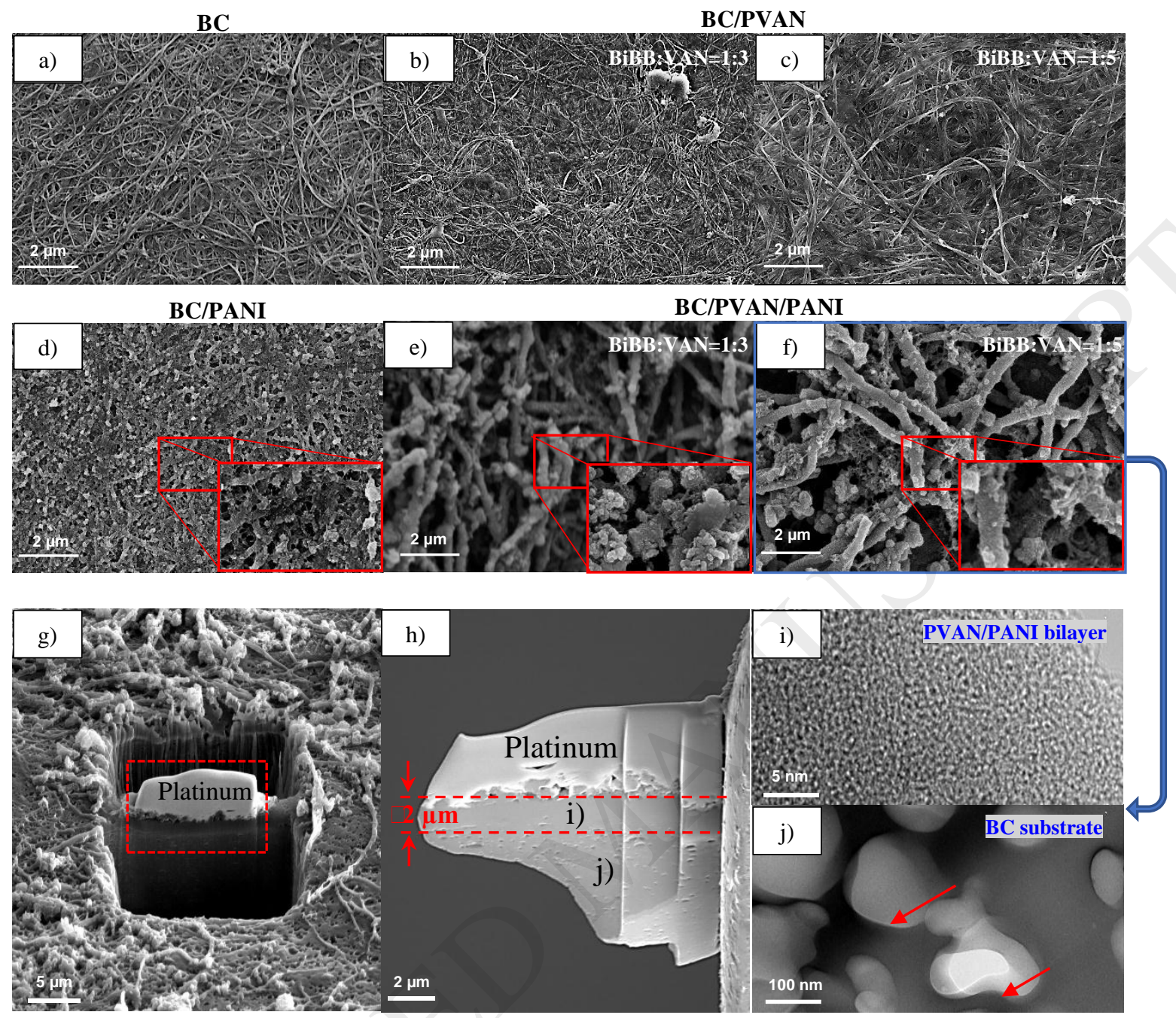

Figure 2. Representative SEM images and respective magnifications of a) un-modified BC

nanofibrous membrane, showing nanofibres with smooth surface, b-c) chemically modified BC membrane with its nanofibrils grafted with PVAN (BC/PVAN). BC nanofibres membrane treated with d) PANI (BC/PANI) and e-f) with PVAN/PANI coating bilayer in two consecutive grafting procedures with PVAN and PANI (BC/PVAN/PANI), illustrating all an increase in the roughness of the $\mathrm{BC}$ nanofibrils surface in contrast to pristine $\mathrm{BC}$ and $\mathrm{BC} / \mathrm{PVAN}$ nanocomposite membranes. b,e) and c,f) BC nanocomposite membranes were produced from molar BiBB:VAN ratios of 1:3 and 1:5, respectively. g-h) FIB/SEM images illustrating the FIB lift-out process used to extract a thin film TEM sample from the bulk BC/PVAN/PANI (BiBB:VAN=1:5) membrane, 
showing the thickness of the upper PVAN/PANI layer of approximately $2 \mu \mathrm{m}$. Corresponding HRTEM images of the selected area in g,h) of i) BC matrix and j) of the PVAN/PANI bilayer. The red arrows in $\mathrm{j}$ ) indicate pores of $\mathrm{BC}$ substrate.

The microstructural analysis cross micro- to nanoscale of PVAN/PANI functionalized BC was further examined in detail with FIB/SEM (Figure 2g,h), which has yield the high resolution TEM (HRTEM) images in the regions of PVAN/PANI coating and BC matrix (Figure 2i,j). As clearly shown, the porous BC substrate (Figure $2 \mathrm{~h}, \mathrm{j}$ ) was covered with a uniform and homogenously PVAN/PANI coating of ca. $2 \mu \mathrm{m}$ thick (Figure 2h,j). Further examination of microstructural characteristics of the PVAN/PANI bilayer (Figure 2i), confirms the formation of an intact coating well-adhered to BC substrate with no signs of visible defects ( $\mathrm{Wu}, \mathrm{Li}$, Liang, Chen, \& Yu, 2013). However, as expected the pores still remained in the substrate of BC network (Wu et al., 2013), with variable pore size of up to few hundred of nanometers, as seen in Figure 2j. This can potentially result in some remarkable properties, for instance, high mechanical strength, and biocompatibility, while still maintaining its high water holding capacity to accommodate ionic solutions for improved conductivity (Jeon, Oh, Kee, \& Kim, 2010; Loh \& Choong, 2013; Shah, Ul-Islam, Khattak, \& Park, 2013).

The TEM X-ray elemental mapping at the interface between PVAN/PANI and BC substrate (Figure 3a) showed a N-enriched coating on the nanocomposite surface (Figure 3e). The general elevation of $\mathrm{N}$ concentration in the surface region implies the presence of the PVAN/PANI coating bilayer, that are nitrogen-containing compounds, as schematically shown in Figure 1c. It is however difficult to distinguish the PVAN/PANI interfaces because PANI is cross-linked with PVAN through -NH- bonds, resulting in a homogenous and gradual change at the interface. Carbon $(\mathrm{C})$ and oxygen $(\mathrm{O})$ are also uniformly distributed across the section in the selected area. 
$\mathrm{Br}$ is also present which can be ascribed to $\mathrm{BiBB}$ initiator indicated its successful impregnation onto BC backbone to allow later attachment of PVAN brushes (Figure 1c). Residual amounts of $\mathrm{Cl}^{-}$from $\mathrm{HCl}$ detected mainly on the surface are associated with PANI synthesis procedure in $\mathrm{HCl}$ medium, which confirms the existence of PANI in that region (Chen et al., 2017).

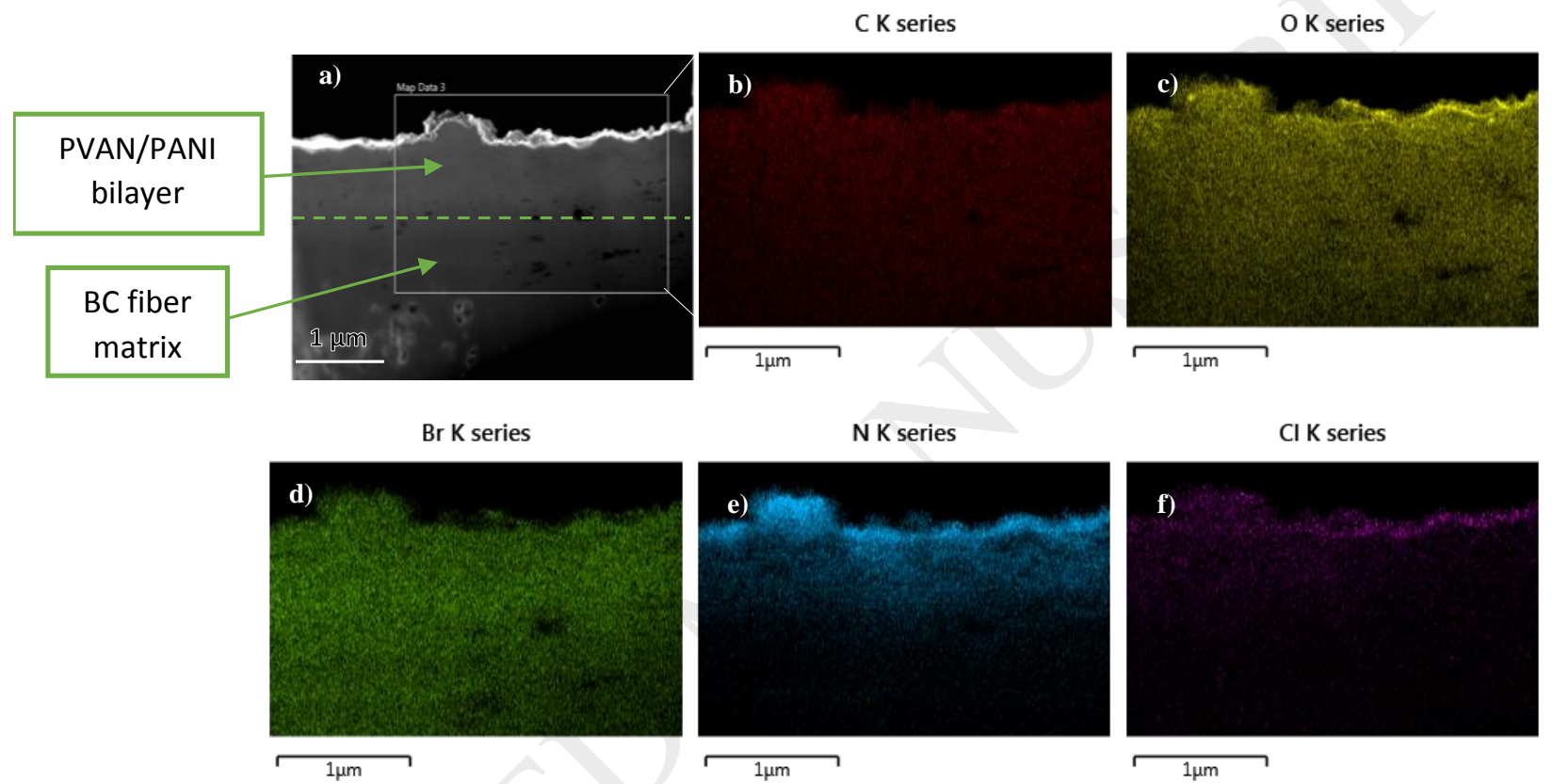

Figure 3. a) STEM image showing the microstructure of PVAN/PANI-grafted BC at a cross sectional view, as illustrated in Figure 2g.1. b-f) corresponding EDX maps of the selected area in a).

XPS spectra corroborated the TEM X-ray mapping results with an N-enriched shell zone (Figure 4a-d). The core-level spectrum of carbon 1s (C1s) in BC revealed typical binding energies $(\mathrm{BE})$ from pristine $\mathrm{BC}$ at $285.0 \mathrm{eV}(\mathrm{C}-\mathrm{C} / \mathrm{C}-\mathrm{H}), 286.6 \mathrm{eV}(\mathrm{C}-\mathrm{O})$ and $288.1 \mathrm{eV}(\mathrm{O}-\mathrm{C}-\mathrm{O})$ (Figure 4a.2) (Persin et al., 2013). SI-ATRP is strongly dependent on the efficient esterification of $\mathrm{BC} \mathrm{OH}$ groups through BiBB (Çankaya, 2015). The successful immobilization of the initiator 
can be testified from the new peak emerged at $71 \mathrm{eV}$ (Figure 4b.1) assigned to bromide $3 \mathrm{~d}$ (Br3d) core shell level and from the new de-convoluted C1s peak (Figure 4b.2) attributed to the $\mathrm{O}-\mathrm{C}=\mathrm{O}$ bond (at $289.4 \mathrm{eV}$ ) proceeded from $\mathrm{BC}$ esterification (P.-S. Liu et al., 2009). C-Br bond may have also contributed to the intensity read at $285.0 \mathrm{eV}$ (Belgacem, Czeremuszkin, Sapieha, \& Gandini, 1995). The degree of substitution (DSS) of BiBB can be inferred from the content of the $\mathrm{C} 1 \mathrm{~s}$ associated to the ester bond $(\mathrm{O}-\mathrm{C}=\mathrm{O})$ from the following equation (Equation 3 ) (Belgacem et al., 1995):

$D S S=\frac{-\% C(O-C=O) \times M_{A G U}}{\% C(O-C=O) \times M_{\text {grafts }}-M_{C}}$,

where $\% \mathrm{C}(\mathrm{O}-\mathrm{C}=\mathrm{O})$ is the atomic percentage of $\mathrm{C} 1 \mathrm{~s}$ of the ester group, $\mathrm{M}_{\mathrm{AGU}}$ is the mass of the anhydro-glucose unit $\left(162 \mathrm{~g} \cdot \mathrm{mol}^{-1}\right), \mathrm{M}_{\text {grafts }}$ is the mass of the graft moiety and $\mathrm{M}_{\mathrm{C}}$ is the mass of carbon. From this equation, the DSS of BC-BiBB is $77 \%$, which means about $77 \%$ of $\mathrm{BC}$ growing sites were readily available for PVAN grafting which shows a good agreement with the reported literature (Joubert, Musa, Hodgson, \& Cameron, 2014; Hongle Wang, Fu, Wang, Shao, \& Qin, 2017). Moreover, it is very unlikely that every hydroxyl group would be equally accessible for modification as consequence, among others, of $\mathrm{BC}$ drying process prior to $\mathrm{BiBB}$ immobilization. 

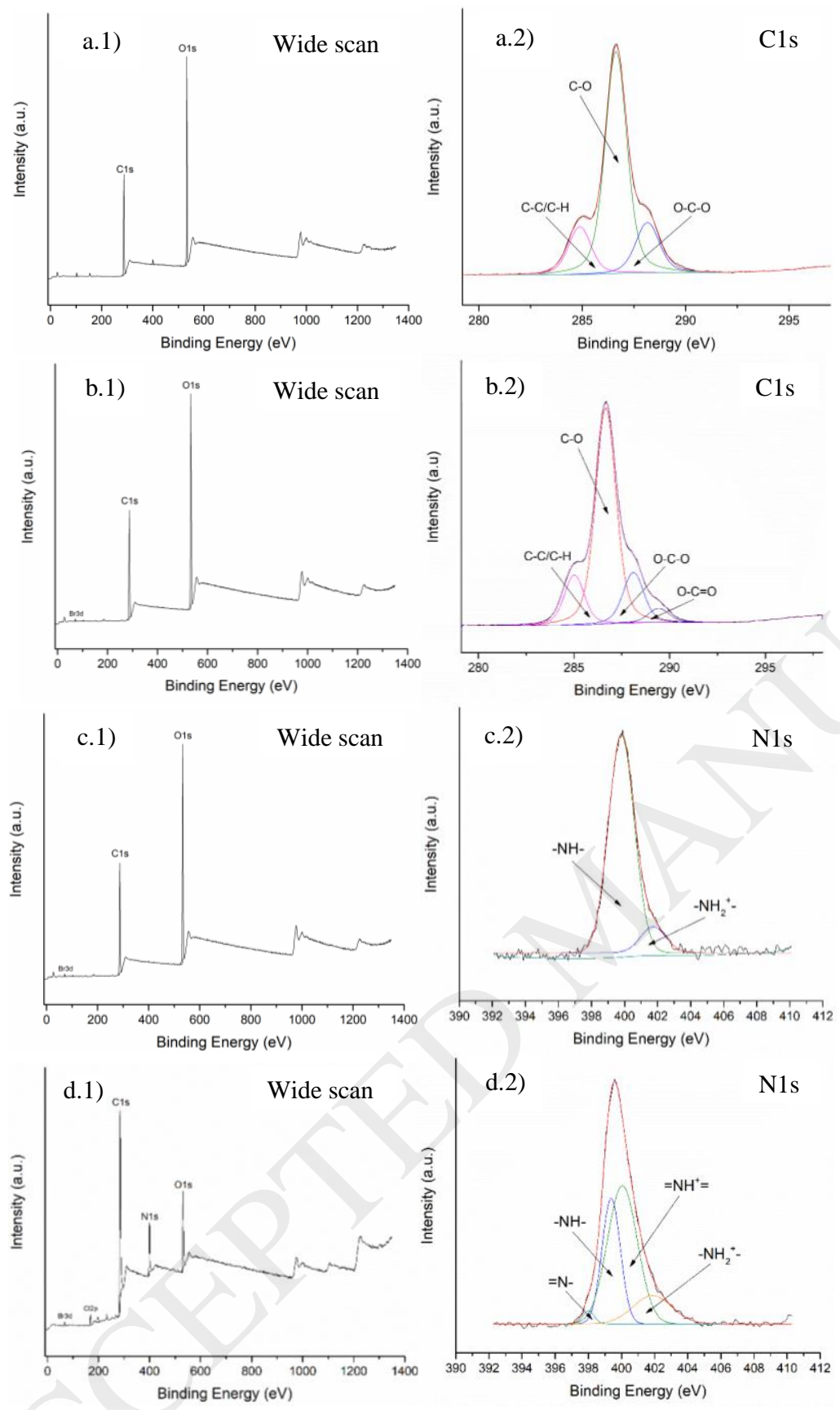

Figure 4. Typical wide scans of a.1) BC, b.1) BC-BiBB, c.1) BC/PVAN (BiBB:VAN=1:5) and d.1) BC/PVAN/PANI (BiBB:VAN=1:5). High resolution C1s scans of a.2) BC and b.2) BC$\mathrm{BiBB}$, and high resolution N1s scans of c.1) BC/PVAN (BiBB:VAN=1:5) and d.1) BC/PVAN/PANI (BiBB:VAN=1:5). 
The resultant spectra in Figure 4c,d confirmed successful the PVAN and PANI grafting onto $\mathrm{BC}$ membranes evidenced by the presence of BE corresponding to nitrogen 1s (N1s) and higher relative peak intensities of $\mathrm{C} 1 \mathrm{~s}$, reflecting the enrichment in carbon content from the aromatic rings that composes both PVAN and PANI (Figure 2c). The N1s core-level of BC/PVAN could be curved-fitted into two individual peaks at $399.8 \mathrm{eV}$ and $401.7 \mathrm{eV}$, ascribed to the neutral ($\mathrm{NH}-)$ and positively charged $\left(-\mathrm{NH}_{2}{ }^{+}\right)$amine group, respectively. Further functionalization with PANI led to an expected increase in N1s content, that can be de-convoluted into four peaks representing four components with BE corresponding to the quinoid imine $(=\mathrm{N}-)$ at $398.0 \mathrm{eV}$, benzenoid amine $(=\mathrm{N}=)$ at $399.3 \mathrm{eV}$, and positively charged nitrogen atoms at $400.1 \mathrm{eV}$ and $401.9 \mathrm{eV}\left(=\mathrm{NH}^{+}=\right.$and $-\mathrm{NH}_{2}{ }^{+}$, respectively) (Tanwar \& Ho, 2015; Tong et al., 2014). The doping level of PANI can be estimated from the fractional areas of protonated nitrogen atoms. The fractional areas of these four peaks were estimated to be $0.02,0.30,0.54$ and 0.14 , which indicates the doping level can reach as high as 68\% (Tanwar \& Ho, 2015).

The relative amount of both PVAN and PANI on BC surface could be inferred from the $\mathrm{N} 1 \mathrm{~s} / \mathrm{C} 1 \mathrm{~s}$ ratio (Table 1). As anticipated, higher $\mathrm{N} 1 \mathrm{~s} / \mathrm{C} 1 \mathrm{~s}$ intensity was perceivable with higher VAN feeding ratio. After aniline polymerization, $\mathrm{N} 1 \mathrm{~s} / \mathrm{C} 1 \mathrm{~s}$ ratio doubled from 0.07 to 0.15 for BiBB:VAN=1:5 membranes. Interestingly, when lower VAN monomer contents were used, $\mathrm{N} 1 \mathrm{~s} / \mathrm{C} 1 \mathrm{~s}$ ratio decreased, which implies that higher VAN amounts promote higher PANI yields. 
Table 1. Elemental composition (atomic percentage, at $\%$ ) of $\mathrm{BC}, \mathrm{BC}-\mathrm{BiBB}, \mathrm{BC} / \mathrm{PVAN}$ and BC/PVAN/PANI composites extracted from XPS analysis.

\begin{tabular}{lllllll}
\hline & & C1s & O1s & Br3d & N1s & N1s/C1s \\
\hline BC & - & 58.3 & 38.0 & - & - & - \\
BC-BiBB & - & 59.8 & 39.3 & 0.4 & - & - \\
BC/PVAN & BiBB:VAN=1:3 & 69.4 & 25.6 & - & 4.3 & 0.06 \\
& BiBB:VAN=1:5 & 68.8 & 23.1 & 2.3 & 4.8 & 0.07 \\
BC/PVAN/PANI & BiBB:VAN=1:3 & 79.5 & 15.4 & - & 3.6 & 0.04 \\
& BiBB:VAN=1:5 & 73.7 & 12.0 & 0.5 & 11.1 & 0.15 \\
\hline
\end{tabular}

\subsection{Evaluation of electrical properties of BC/PVAN/PANI nanocomposites}

The conductivity of PANI-based membranes presents a trend of increasing subject to the nanofibers density, PVAN grafting yield, as well as to changes in COP parameters. The

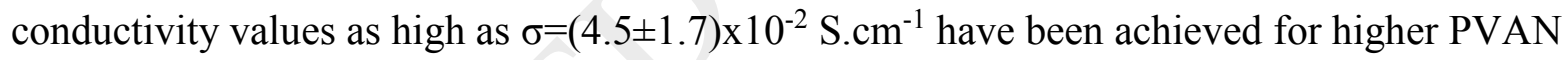
grafting yield on the denser side of the membranes.

The kinetic of PANI synthesis determines the overall conducting properties, which depend on several parameters according to the following equation (Equation 4) (I. Y. Sapurina \& Shishov, 2012):

$$
-\frac{d[A N I]}{d t}=k_{1}[A N I][O x]+k_{2}[A N I][P]
$$

with $[\mathrm{ANI}],[\mathrm{Ox}],[\mathrm{P}]$ standing for monomer, oxidant (i.e. [APS]) and polymer concentrations, respectively, where $\mathrm{k}_{1}$ and $\mathrm{k}_{2}$ are constants. $\mathrm{k}_{1}$ accounts for the induction period, while $\mathrm{k}_{2}$ reflects the contribution of both acid concentration and surface area. It is worthwhile to mention that an increased polymerization rate, and hence PANI yield, does not always lead to the formation of 
highly conductive structures, although it may indirectly have contribution under certain conditions, providing that suitable electronic band structures are created (I. Sapurina \& Stejskal, 2008).

\subsubsection{Effect of BC porosity and PVAN grafting on electrical conductivity}

The intrinsic PANI conductivity can be attributed to the long-range of delocalized charge carriers system arising from the oxidation of nitrogen atoms that serve as oxidation centers (Focke, Wnek, \& Wei3, 1987). Variations of parameters in the polymerization, including the surface area available for the reaction, have a definitive effect on the PANI size and shape, which induces some changes in this delocalized system (Bhadra, Singha, Chattopadhyay, \& Khastgir, 2007; I. Y. Sapurina \& Shishov, 2012). In spite of the widely recognized electrically insulating properties, $\mathrm{BC}$ not merely provides a substrate for allocating PVAN/PANI bilayer as a cohesive and uniform coating, but also acts as a catalyst of aniline polymerization as such increases its growth rate. In addition, it furnishes an appropriate 3D porous system as a path for efficient charge carrier flow. In Figure 5, PVAN treated membranes showed a comprehensive higher value of conductivity up to one order of magnitude than those non-treated BC/PANI. The measurements from all samples revealed also a trend of a comparable difference in the conductivity on both sides of the membrane that is correlated with the asymmetry of BC network (Bäckdahl et al., 2006; Ruan et al., 2016). This asymmetry of the membrane is related with BC synthesis procedure. Under static conditions, a pellicle is formed in the medium surface, which grows downwards. Higher oxygen and carbon sources available for bacteria at the liquid-air interface leads to greater yield of production of cellulose fibers of compact structure, in contrast, less oxygen and carbon are available inside the culture medium, resulting in reduced yield of 
production of cellulose fibers causing a more porous structure. Assuming a uniform PANI coating was formed, the side of $\mathrm{BC}$ membranes with a compact packing of $\mathrm{BC}$ fibers would reflect in a larger area covered by PANI as a continuous film with higher concentration of charge carriers and thus, resulting in a higher conductivity in comparison with the side with a porous structure of BC fibers (Figure 5). Different surface areas with simultaneous changes on COP parameters are expected to reflect additional modifications in PANI properties, as such this leads to a multiplicity of PANI synthetic rates (I. Y. Sapurina \& Shishov, 2012). Similar to BC, PVAN is not inherently conductive as PANI (Balint, Cassidy, \& Cartmell, 2014). However, the incorporation of PVAN and subsequent increase of its content led to an augmented conductivity up to one order of magnitude. For instances, on the compact side of the membrane it increased from $(3.7 \pm 0.5) \times 10^{-3}$ (BC/PANI) to $(5.2 \pm 0.9) \times 10^{-3}$ (BiBB:VAN=1:3) and then to $(2.2 \pm 0.6) \times 10^{-2}$ $\mathrm{S} . \mathrm{cm}^{-1}(\mathrm{BiBB}: \mathrm{VAN}=1: 5)$, respectively. This increased conductivity might have been resulted from the formation of more organized PANI structures that, among others, elongated the polyconjugated system by enhancing the charge carrier mobility as that of the doping agent (HCl) (Skotheim \& Reynolds, 2007). 


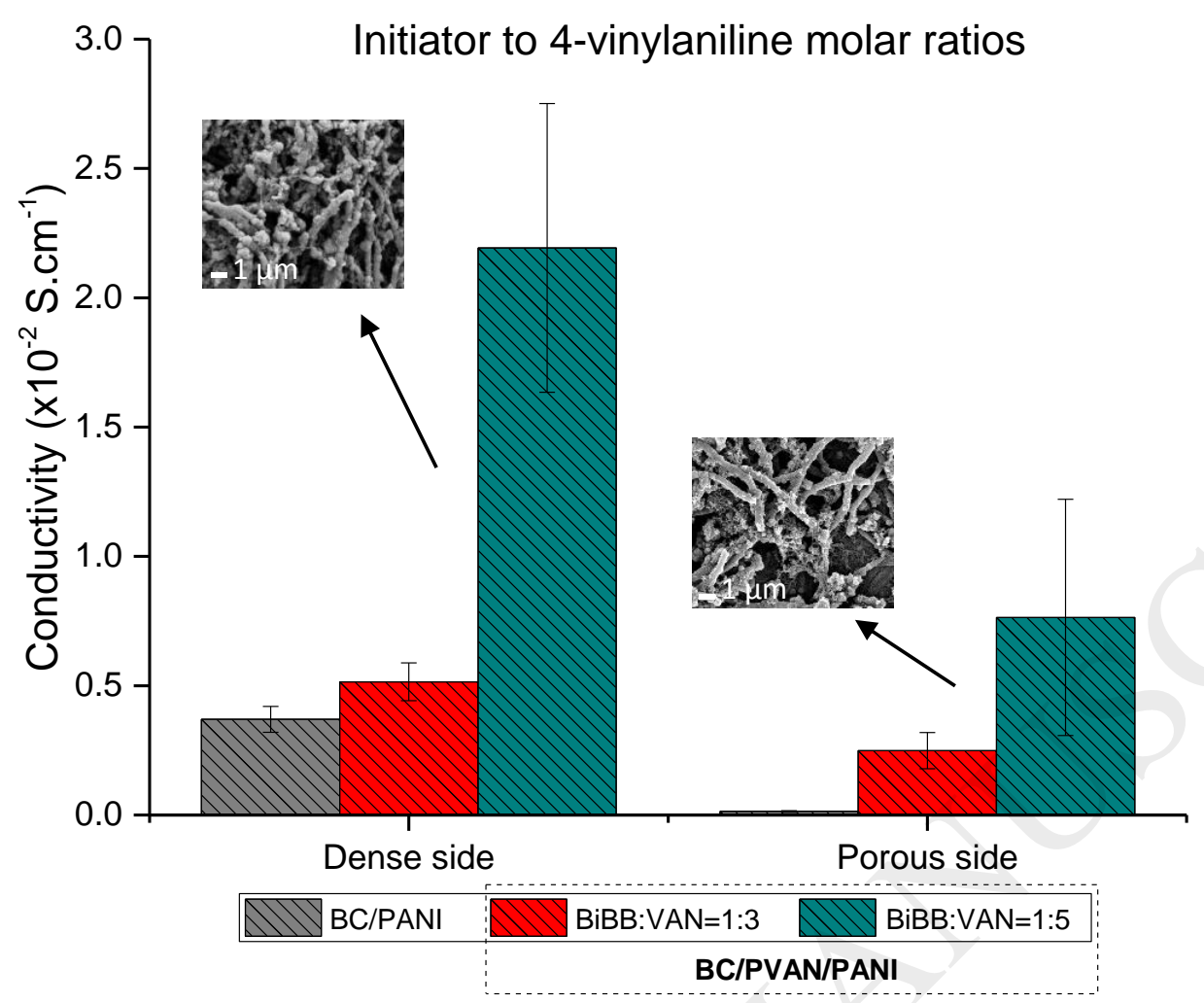

Figure 5. Electrical conductivity of BC/PANI, and BC/PVAN/PANI membranes with different $\mathrm{BC}$ to VAN molar ratios, the embedded images show the morphology of the selected area.

\subsubsection{Effect of aniline polymerization parameters on electrical conductivity}

The effect of COP parameters on the electrical conductivity of the PANI/PVAN functionalized BC composites is summarized and presented in Figure 6. Studies reported in the literature up to now on PANI synthesis have suggested that the strong acidic media ( $\mathrm{pH}$ below 2.5) promotes highly conductive PANI structures, i.e. in the emeraldine oxidation form (Duid \& Mandid, 1992; Stejskal, Sapurina, \& Trchová, 2010). Herein, higher conductivity was observed on the dense side with the samples prepared in the solutions containing $1 \mathrm{M} \mathrm{HCl}$ in comparison with those prepared in $0.5 \mathrm{M} \mathrm{HCl}$. This was likely to be related to a higher degree of protonation products of aniline oxidation and may also be correlated with an increase of the 
crystallite size together with a decrease in d-spacing and interchain separation of PANI (Clasen, Sultanova, Wilhelms, Heisig, \& Kulicke, 2006; I. Y. Sapurina \& Shishov, 2012). Slightly higher conductivity at $0.5 \mathrm{M}$ on the porous side can be observed, probably related with a balanced effect of the surface area. The conductivity under both conditions fell, however, into the same range due to the slightly increase of $\mathrm{pH}$ value of the media from 0 to 0.3 when decreasing the concentration of acid from $1 \mathrm{M}$ to $0.5 \mathrm{M}$. The variation of molar ratio of ammonium persulfate (oxidant) to aniline (monomer) also influenced the final conductivity of the synthesized membranes. Ammonium persulfate is considered as a strong oxidizing agent, which is able to oxidize both aniline monomer and the growing chain during polymerization. According to the chemical reaction, $[\mathrm{APS}]:[\mathrm{ANI}]=1.25$ is the stoichiometric ratio that reflects the minimum oxidant amount to be used for complete monomer oxidation, which is expected to yield more conductive structures. However, the highest conductivity was obtained when using the lowest molar APS:ANI feeding ratio (APS:ANI=1), this is likely associated with the over-oxidation of aniline that has enabled the formation of fully oxidized pernigraniline salt with low conductivity, instead of the partially oxidized emeraldine salt with high conductivity (E. J. Jelmy et al., 2013). This effect has been reported in the literature for oxidant to monomer ratios over 1.15, which is comparable with the results herein obtained (Cortés \& Sierra, 2006; Mahalakshmi \& Vedhi, 2014). Extending the polymerization time, e.g. from 3 hours to 6 hours, the conductivity of the PVAN/PANI functionalized BC membranes increased from (1.0 \pm 0.6$) \times 10^{-2} \mathrm{~S} . \mathrm{cm}^{-1}$ up to $(2.2 \pm 0.6) \times 10^{-2}{\mathrm{~S} . \mathrm{cm}^{-1}}^{-1}$ accordingly. However, further prolonged time of polymerization was hardly shown any significant improvements in their conductivity on the dense side of the samples because higher PANI molecular weight has induced the formation of certain defects that causes modification of the delocalized system which has 
ultimately reduced the conductivity (Bhadra et al., 2007; Xie, Ma, \& Feng, 2000). In contrast, on the porous side there is an apparent trend to increase, ascribed to a slower PANI loading process with appropriate band structure that may be able to increase for longer reaction times. Greater conductive values were also found to be associated with larger monomer concentration. From $[\mathrm{ANI}]=0.2 \mathrm{M}$ to $0.7 \mathrm{M}$, the conductivity of the $\mathrm{BC}$ composites increased significantly, at which the highest value of $(4.5 \pm 2.8) \times 10^{-2}{\mathrm{~S} . \mathrm{cm}^{-1}}$ was achieved. Increasing monomer concentration leads to an increased yield, thus a ultimate augmented BC/PVAN nucleation sites for continuous PANI growth of proper band structure (Bhadra et al., 2007; Xing, Zhao, Jing, \& Wang, 2006). 

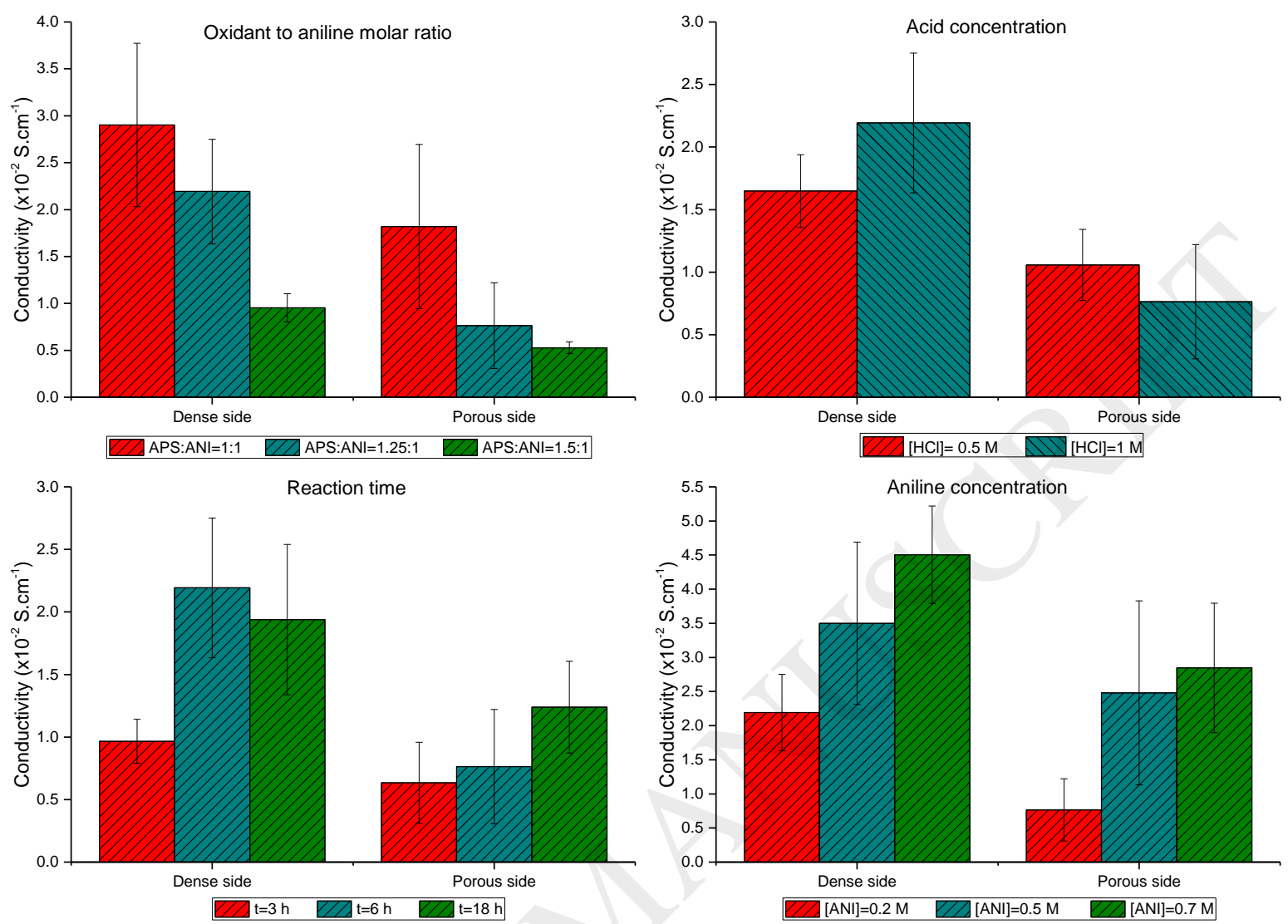

Figure 6. Differences on the electrical conductivity of BC/PVAN/PANI composites with variation of aniline polymerization parameters: molar ratio APS:ANI, acid concentration, reaction time and aniline concentration.

Overall, BC/PVAN/PANI nanocomposites revealed reasonable conductivity which may suits many potential bioelectronic applications, that was explicitly improved by means of PVAN incorporation and appropriate adjustment of COP parameters. The different conductivity seen on both sides of the membrane may be beneficial for more singular applications where applicable. 


\subsection{Thermal stability of PVAN/PANI coatings}

Thermogravimetric analysis (TGA) was performed from room temperature up to $800{ }^{\circ} \mathrm{C}$ on pure $\mathrm{BC}$ and the PVAN/PANI functionalized composite $\mathrm{BC}$ membranes to assess their thermal stability (Figure 7). As measured through weight loss, the thermal decomposition of these membranes after thermal loading follows a similar trend with the temperature increase, consisting of three main stages (Borsoi, Zattera, \& Ferreira, 2016). In the first stage, the weight loss of $\mathrm{BC}$ and $\mathrm{BC} / \mathrm{PVAN}$ membranes took place from room temperature to $\sim 150^{\circ} \mathrm{C}$, but the degradation occurred from room temperature to $100{ }^{\circ} \mathrm{C}$ for BC/PVAN/PANI membranes. This is concerned with some moisture remaining inside the membranes, in the form of either water and/or dopant $\mathrm{HCl}$ as has been reported elsewhere (D. Y. Liu, Sui, \& Bhattacharyya, 2014). In the second stage, a drastic weight reduction in the pure $\mathrm{BC}$ membranes was found between 250 and $375^{\circ} \mathrm{C}$, whereas in $\mathrm{BC} / \mathrm{PVAN}$ and $\mathrm{BC} / \mathrm{PVAN} / \mathrm{PANI}$ membranes the temperature range for the abrupt weight loss has started earlier, i.e. $200-350{ }^{\circ} \mathrm{C}$ and $175-250{ }^{\circ} \mathrm{C}$, respectively. This can be associated with the main chain decomposition of crystalline and amorphous regions of $\mathrm{BC}$ into D-glucopyranose monomer and further into free radicals (W. Hu et al., 2011). In the third or final degradation stage as can be identified from 375,350 and $250^{\circ} \mathrm{C}$ in $\mathrm{BC}, \mathrm{BC} / \mathrm{PVAN}$ and $\mathrm{BC} / \mathrm{PVAN} / \mathrm{PANI}$ membranes respectively, the weight loss was insignificant and gradually reaching a relative steady level owing to the residual main chain decomposition (F. Wang et al., 2016). However, the onset degradation temperature varied from $362{ }^{\circ} \mathrm{C}$ in $\mathrm{BC}$ to $241{ }^{\circ} \mathrm{C}$ in $\mathrm{BC} / \mathrm{PVAN}$ and $207^{\circ} \mathrm{C}$ in $\mathrm{BC} / \mathrm{PVAN} / \mathrm{PANI}$ membranes, while the degradation of the third stage was stabilized at the temperature $20{ }^{\circ} \mathrm{C}$ in $\mathrm{BC}$ to $30^{\circ} \mathrm{C}$ in the composite membranes. Noticeably, the remaining mass of both $\mathrm{BC} / \mathrm{PVAN}$ and $\mathrm{BC} / \mathrm{PVAN} / \mathrm{PANI}$ composite membranes was approximately $30 \%$ greater than that of pure $\mathrm{BC}$ membranes. 


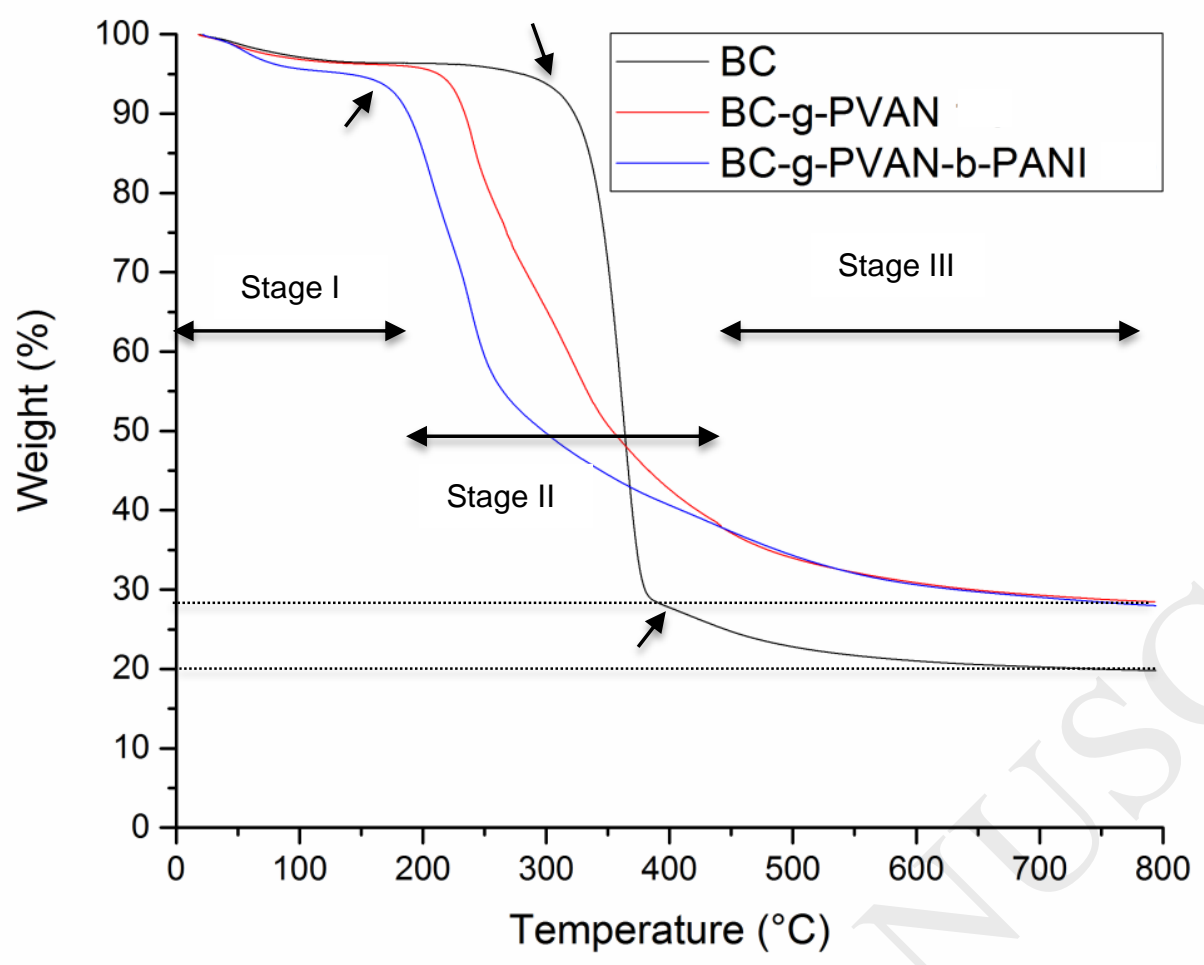

Figure 7. Representative thermogravimetric curves of BC, BC/PVAN 1:5 and BC/PVAN/PANI 1:5 membranes measured from room temperature to $800{ }^{\circ} \mathrm{C}$. Three main stages of weight loss identified: Stages I, II and II.

\subsection{Cytocompatibility with SVZ cells}

To verify the cytocompatibility of the newly developed functionalized $\mathrm{BC}$ nanocomposites for neural applications, neural stem cells from the subventricular zone (SVZ) of postnatal mice were incubated with the grafted BC membranes for 7 days, as such their responses were evaluated and compared with that of pristine $\mathrm{BC}$ and tissue culture treated plastic (TCTP), which was used as a control. Representative images of the SVZ cells on the functionalised BC are depicted in Figure 8 , in which live cells are stained green with calcein-AM and dead cells red with propidium iodine. The cell viability and cell number relative to the TCTP are shown in Figure 8i,j. 20,000 cells per well were seed equally to all BC composites and TCTP. After 7 days of culture, over 
$80 \%$ of cells were viable in all conditions, reaching up to approximately $90 \%$ of viability on PANI-reinforced BC, which suggests the substrates are not cytotoxic. However, with 95\% confidence level, there is an apparent lower number of cells on BC/PVAN/PANI nanocomposites compared to that of control TCTP (Figure 8a-h,j). This could be due to the presence of some residual chemicals after $\mathrm{COP}$, including unreacted aniline monomer and oligomers, oxidant and acid, although the grafted samples had been pre-washed extensively before being used for cell culture. In particular $\mathrm{HCl}$, as seen with the presence of $\mathrm{Cl}^{-}$ions in STEM x-ray mapping (Figure 3h) and XPS wide spectra of BC/PVAN/PANI (Figure 4d.1). Considering the nano-porous structures of the composite, the pre-wash steps relying on mass diffusion might not have efficiently removed all the residual chemicals and this may have led $\mathrm{HCl}$ not to be properly neutralized, creating an acidic environment which is known not to be favourable for cell growth (Rotin, Robinson, \& Tannock, 1986), but further investigation will be needed to confirm this. 


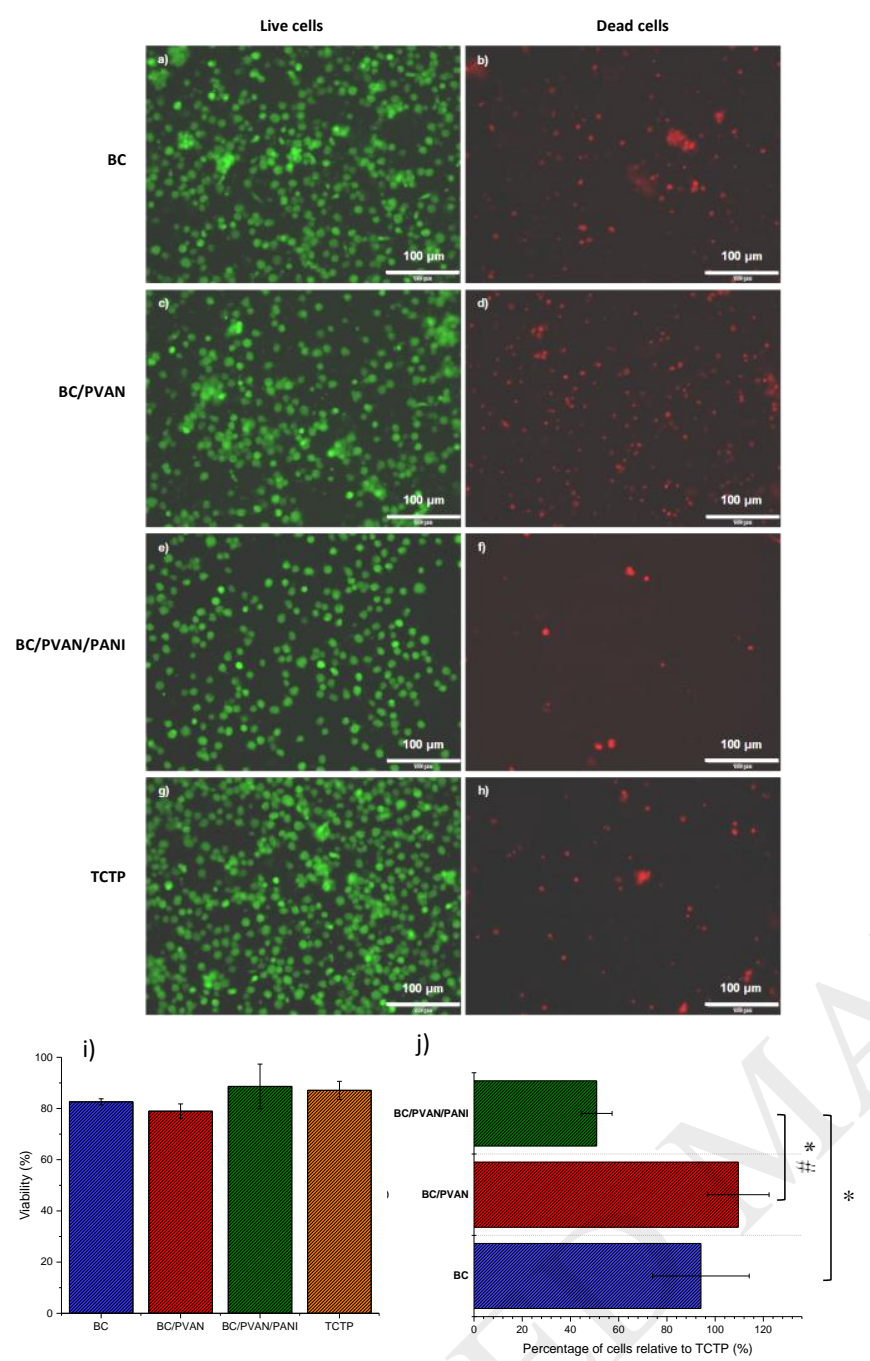

Figure 8. Cell viability of SVZ cells on BC composites after 7 days of incubation. Live and dead staining of a,b) BC, c,d) BC/PVAN, e,f) BC/PVAN/PANI and g,h) TCTP, and i) corresponding percentage of viable cells and j) percentage of cells relative to TCTP, with standard deviation error bars. Live cells are marked as green and dead cells are marked as red. Significance is denoted as $* p<0.05$ and $\# p<0.01$.

Despite what has been observed, the cell viability was not affected by the functionalized BC membranes and appeared similar to that of the control without statistical significant difference. It is very promising to see that almost $90 \%$ of cells were viable on BC/PVAN/PANI 
composites. Further, an observable higher number of cells on BC/PVAN composites indicates PVAN provides good support for cell proliferation, which could be attributable to the improved hydrophilic properties (Yuan et al., 2012). This suggests that the composites, in particular, PVAN/PANI functionalized BC with enhanced conductivity do not cause any cytotoxicity.

\subsection{Potential applications}

On the basis of multi-layered structure, we have developed with above BC/PVAN/PANI system, an enclosed $\mathrm{BC}$ covered both sides with electrical conductive PANI coatings that may be considered for constructing a bioelectronic device capable of stimulating and monitoring the interfacial behavior. The possible switch of the electrochemical performance of PANI caused by redox reactions, as demonstrated in literature (Shi et al., 2014) and confirmed in our current ongoing study, can act as pathway for appropriate signal amplification. Such functionalized BC can provide not only the desirable morphological and electrical properties due to the PVAN interlayer but may also significantly improve the biocompatibility. The elevated thermal stability of electrical conductive BC nanocomposites ensures thermal feasibility from electronic ( $\square 100$ $\left.{ }^{\circ} \mathrm{C}\right)$ and biological point of views $\left(37^{\circ} \mathrm{C}\right)$. It is therefore believed this may well perform and act as an efficient biosystem for building neural interfaces, by effectively detecting, recording and amplifying electrical signals from neurons that has an estimated electrical conduction of $\sigma=7 \times 10^{-}$ ${ }^{4}$ C.m-2 (McCandless, 1997; Peters, Stinstra, \& Leveles, 2004). This will ultimately promote cell adhesion and growth by means of a substrate with suitable interconnected porosity and pore size, enabling cell migration and proper flow of nutrients. The conductive PANI surface layer can detect nerve impulses caused by ionic depolarization of the neuron membrane, and subsequently 
be converted into an electrical signal (transduction) and transmitted with aids of the excellent mass transport capacity of BC network, to be readable with a externally connected electrical device, as schematically represented in Figure 9.

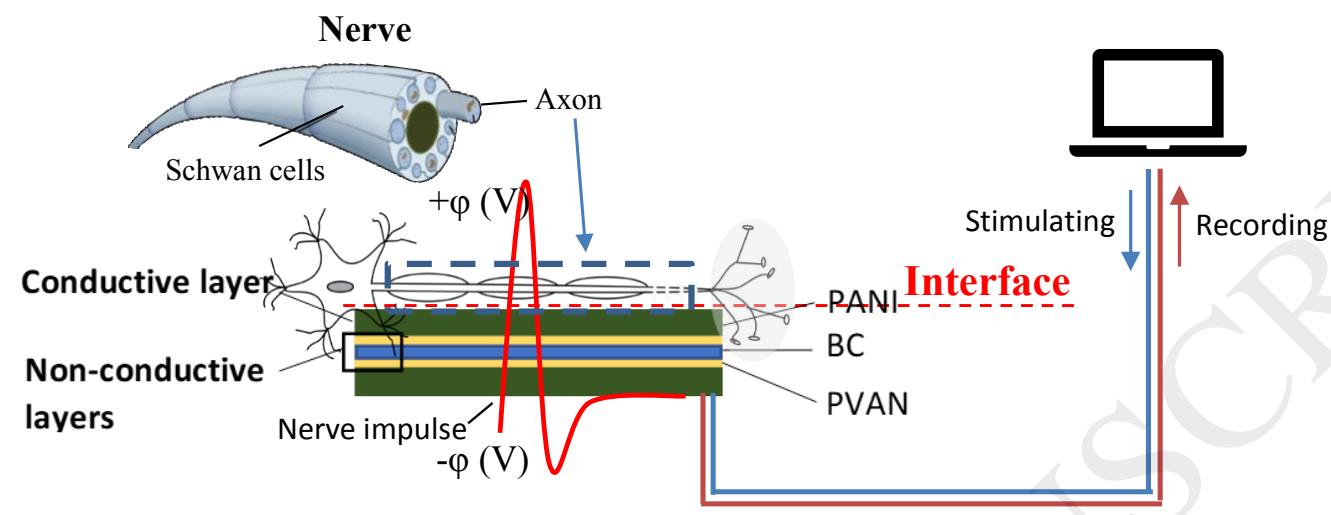

Figure 9. Schematic representation of flexible electrical conductive BC/PVAN/PANI nanocomposite membranes, biologically interfacing with neurons for efficient nerve impulse conduction.

\section{Conclusions}

PVAN/PANI functionalized BC nanocomposite membranes with enhanced electrical conductivity and cell viability were successfully synthesized through ATRP and COP reactions for potential construction of bioelectronic interfaces. The chemical analysis confirmed the actual composition of PVAN/PANI which had been grafted onto BC nanofibres. Especially, an approximate $2 \mu \mathrm{m}$ of an intact PVAN/PANI bilayer was formed uniformly on the surface of BC membranes. The electrical properties of the newly developed $\mathrm{BC}$ membranes were closely related to the supramolecular PANI structures produced during the chemical reaction. The PVAN interlayer inserted between PANI and BC enable an increase of PANI production with a more homogeneous distribution of its structural units in the form of nanofibers-/nanorods-like 
shape, which can also be strengthened through denser PVAN brushes. This could be potentially applied onto other relevant substrates. Polymerization process to incorporate PVAN/PANI bilayer can be chemically controlled and optimized to achieve the desirable properties. It has been found that the polymerization with higher VAN monomer contents, and higher $\mathrm{HCl}$ and aniline concentrations for extended reaction time yielded a higher electrical conductivity of the BC/PVAN/PANI nanocomposites. Cell viability tests have indicated there had been no visible signs of cytotoxicity for SVZ cells after 7 days of culture, which is crucial in terms of building any potential bioelectronic interfaces. Furthermore, the PVAN/PANI coated BC nanocomposites were proven to be thermally stable up to $225^{\circ} \mathrm{C}$ confirming their suitability for both electronics and body environments. These novel BC/PVAN/PANI nanocomposites can be particularly applicable for nervous system, such as those required delicate neural interfaces, biosensors, displays and smart drug-delivery systems. The potential application of the newly developed conductive and biocompatible layer on $\mathrm{BC}$ substrate as neural interface has been demonstrated on the basis of its electrical and biological properties.

\section{Acknowledgments}

This research was supported by a Marie Curie International Research Staff Exchange Scheme Project of the 7th European Community Framework Program (Grant No. PIRSES-GA-2010269113), entitled "Micro-Multi-Material Manufacture to Enable Multifunctional Miniaturized Devices (M6)". The authors also acknowledge the valuable support and inputs to the TEM microstructural analysis by Dr Jing Wang of Wolfson School, and Dr Zhaoxia Zhao of LMCC of Loughborough University, UK, as well as Dr Xiuli Chen for her technical inputs in the initial preparation of polymerization process. 


\section{References}

Abeer, M. M., Mohd Amin, M. C. I., \& Martin, C. (2014). A review of bacterial cellulose-based drug delivery systems: their biochemistry, current approaches and future prospects. The Journal of Pharmacy and Pharmacology, 66(8), 1047-1061. https://doi.org/10.1111/jphp.12234

Alonso, E., Faria, M., Mohammadkazemi, F., Resnik, M., Ferreira, A., \& Cordeiro, N. (2018). Conductive bacterial cellulose-polyaniline blends: Influence of the matrix and synthesis conditions. Carbohydrate Polymers, 183, 254-262. https://doi.org/10.1016/J.CARBPOL.2017.12.025

Andrei, V., Bethke, K., Madzharova, F., Beeg, S., Knop-Gericke, A., Kneipp, J., \& Rademann, K. (2017). Size Dependence of Electrical Conductivity and Thermoelectric Enhancements in Spin-Coated PEDOT:PSS Single and Multiple Layers. Advanced Electronic Materials, 3(2), 1600473. https://doi.org/10.1002/aelm.201600473

Andrei, V., Bethke, K., Madzharova, F., Bronneberg, A. C., Kneipp, J., \& Rademann, K. (2017). In Situ Complementary Doping, Thermoelectric Improvements, and Strain-Induced Structure within Alternating PEDOT:PSS/PANI Layers. ACS Applied Materials \& Interfaces, 9(38), 33308-33316. https://doi.org/10.1021/acsami.7b10106

Bäckdahl, H., Helenius, G., Bodin, A., Nannmark, U., Johansson, B. R., Risberg, B., \& Gatenholm, P. (2006). Mechanical properties of bacterial cellulose and interactions with smooth muscle cells. Biomaterials, 27(9), 2141-2149. https://doi.org/10.1016/j.biomaterials.2005.10.026

Balint, R., Cassidy, N. J., \& Cartmell, S. H. (2014). Conductive polymers: towards a smart biomaterial for tissue engineering. Acta Biomaterialia, 10(6), 2341-2353. 
https://doi.org/10.1016/j.actbio.2014.02.015

Bandeira, R. M., van Drunen, J., Garcia, A. C., \& Tremiliosi-Filho, G. (2017). Influence of the thickness and roughness of polyaniline coatings on corrosion protection of AA7075 aluminum alloy. Electrochimica Acta, 240, 215-224. https://doi.org/10.1016/J.ELECTACTA.2017.04.083

Belgacem, M. N., Czeremuszkin, G., Sapieha, S., \& Gandini, A. (1995). Surface by XPS characterization and inverse gas of cellulose fibres chromatography. Cellulose, 2(3), 145157. Retrieved from https://link.springer.com/content/pdf/10.1007/BF00813015.pdf Bethke, K., Palantöken, S., Andrei, V., Roß, M., Raghuwanshi, V. S., Kettemann, F., ... Rademann, K. (2018). Functionalized Cellulose for Water Purification, Antimicrobial Applications, and Sensors. Advanced Functional Materials, 28(23), 1800409. https://doi.org/10.1002/adfm.201800409

Bhadra, S., Singha, N. K., Chattopadhyay, S., \& Khastgir, D. (2007). Effect of different reaction parameters on the conductivity and dielectric properties of polyaniline synthesized electrochemically and modeling of conductivity against reaction parameters through regression analysis. Journal of Polymer Science Part B: Polymer Physics, 45(15), 20462059. https://doi.org/10.1002/polb.21175

Borsoi, C., Zattera, A. J., \& Ferreira, C. A. (2016). Effect of cellulose nanowhiskers functionalization with polyaniline for epoxy coatings. Applied Surface Science, 364, 124132. https://doi.org/10.1016/J.APSUSC.2015.12.140

Çankaya, N. (2015). Cellulose Grafting by Atom Transfer Radical Polymerization Method. In Cellulose - Fundamental Aspects and Current Trends. InTech. https://doi.org/10.5772/61707 
Casado, U. M., Aranguren, M. I., \& Marcovich, N. E. (2014). Preparation and characterization of conductive nanostructured particles based on polyaniline and cellulose nanofibers. Ultrasonics Sonochemistry, 21(5), 1641-1648. https://doi.org/10.1016/j.ultsonch.2014.03.012

Chen, Z., Wei, C., Gong, Y., Lv, J., Xu, Z., Hu, J., \& Du, L. (2017). Preparation and Electrochemical Performances of Cellulose Nanofiber/Graphene Nanosheet/Polyaniline Composite Film via in-Situ Polymerization. Int. J. Electrochem. Sci, 12, 6662-6675. https://doi.org/10.20964/2017.07.61

Chiou, N.-R., Lee, L. J., \& Arthur, J. E. (2007). Self-Assembled Polyaniline Nanofibers/Nanotubes. Chemistry of Materials, 19(15), 3589-3591. https://doi.org/10.1021/CM070847V

Clasen, C., Sultanova, B., Wilhelms, T., Heisig, P., \& Kulicke, W.-M. (2006). Effects of Different Drying Processes on the Material Properties of Bacterial Cellulose Membranes. Macromolecular Symposia, 244(1), 48-58. https://doi.org/10.1002/masy.200651204

Cortés, M. T., \& Sierra, E. V. (2006). Effect of synthesis parameters in polyaniline: influence on yield and thermal behavior. Polymer Bulletin, 56(1), 37-45. https://doi.org/10.1007/s00289005-0467-1

Duid, L., \& Mandid, Z. (1992). Counter-ion and pH effect on the electrochemical synthesis of polyaniline. 31 Electroanal. Chem. Elsevier Sequoia S.A, 335, 207-221. Retrieved from https://ac.els-cdn.com/002207289280243W/1-s2.0-002207289280243Wmain.pdf?_tid=dae0673e-127a-11e8-837d00000aacb35f\&acdnat=1518718131_6f0f26f3e251149186db2697cacd8a6b

Focke, W. W., Wnek, G. E., \& Wei3, Y. (1987). Influence of Oxldation State, pH, and 
Counterion on the Conductlvity of Polyaniline. J. Phys. Chem, 91(20), 5813-5818.

Retrieved from https://pubs.acs.org/doi/pdf/10.1021/j100306a059

Fu, G. D., Zhao, J. P., Sun, Y. M., Kang, E. T., \& Neoh, K. G. (2007). Conductive hollow nanospheres of polyaniline via surface-initiated atom transfer radical polymerization of 4vinylaniline and oxidative graft copolymerization of aniline. Macromolecules, 40(6), 22712275. Retrieved from http://scholarbank.nus.edu.sg/handle/10635/63631

Fu, J., Pang, Z., Yang, J., Huang, F., Cai, Y., \& Wei, Q. (2015). Fabrication of polyaniline/carboxymethyl cellulose/cellulose nanofibrous mats and their biosensing application. Applied Surface Science, 349, 35-42.

https://doi.org/10.1016/J.APSUSC.2015.04.215

Ge, D., Ru, X., Hong, S., Jiang, S., Tu, J., Wang, J., ... Shi, W. (2010). Coating metals on cellulose-polypyrrole composites: A new route to self-powered drug delivery system. Electrochemistry Communications, 12(10), 1367-1370. https://doi.org/10.1016/J.ELECOM.2010.07.022

Gupta, T. K., Singh, B. P., Mathur, R. B., \& Dhakate, S. R. (2014). Multi-walled carbon nanotube-graphene-polyaniline multiphase nanocomposite with superior electromagnetic shielding effectiveness. Nanoscale, 6(2), 842-851. https://doi.org/10.1039/C3NR04565J

Guz, N., Fedotova, T. A., Fratto, B. E., Schlesinger, O., Alfonta, L., Kolpashchikov, D. M., \& Katz, E. (2016). Bioelectronic Interface Connecting Reversible Logic Gates Based on Enzyme and DNA Reactions. ChemPhysChem, 17(14), 2247-2255. https://doi.org/10.1002/cphc.201600129

Hu, L., Ren, Y., Yang, H., \& Xu, Q. (2014). Fabrication of 3D Hierarchical MoS2/Polyaniline and MoS2/C Architectures for Lithium-Ion Battery Applications. ACS Applied Materials \& 
Interfaces, 6(16), 14644-14652. https://doi.org/10.1021/am503995s

Hu, W., Chen, S., Yang, Z., Liu, L., \& Wang, H. (2011). Flexible electrically conductive nanocomposite membrane based on bacterial cellulose and polyaniline. The Journal of Physical Chemistry. B, 115(26), 8453-8457. https://doi.org/10.1021/jp204422v

Jasim, A., Ullah, M. W., Shi, Z., Lin, X., \& Yang, G. (2017). Fabrication of bacterial cellulose/polyaniline/single-walled carbon nanotubes membrane for potential application as biosensor. Carbohydrate Polymers, 163, 62-69.

https://doi.org/10.1016/J.CARBPOL.2017.01.056

Jelmy, E. J., Ramakrishnan, S., Devanathan, S., Rangarajan, M., \& Kothurkar, N. K. (2013). Optimization of the conductivity and yield of chemically synthesized polyaniline using a design of experiments. Journal of Applied Polymer Science, 130(2), 1047-1057. https://doi.org/10.1002/app.39268

Jelmy, J., Ramakrishnan, S., Rangarajan, M., \& Kothurkar, N. K. (2013). Effect of different carbon fillers and dopant acids on electrical properties of polyaniline nanocomposites. Bull. Mater. Sci (Vol. 36). Retrieved from https://www.ias.ac.in/article/fulltext/boms/036/01/0037-0044

Jeon, J.-H., Oh, I.-K., Kee, C.-D., \& Kim, S.-J. (2010). Bacterial cellulose actuator with electrically driven bending deformation in hydrated condition. Sensors and Actuators B: Chemical, 146(1), 307-313. https://doi.org/10.1016/J.SNB.2010.02.046

Joubert, F., Musa, O. M., Hodgson, D. R. W., \& Cameron, N. R. (2014). The preparation of graft copolymers of cellulose and cellulose derivatives using ATRP under homogeneous reaction conditions. Chem. Soc. Rev., 43(20), 7217-7235. https://doi.org/10.1039/C4CS00053F

Kaur, G., Adhikari, R., Cass, P., Bown, M., \& Gunatillake, P. (2015). Electrically conductive 
polymers and composites for biomedical applications. RSC Advances, 5(47), 37553-37567. https://doi.org/10.1039/C5RA01851J

Kim, S.-S., Jeon, J.-H., Kim, H.-I., Kee, C. D., \& Oh, I.-K. (2015). High-Fidelity Bioelectronic Muscular Actuator Based on Graphene-Mediated and TEMPO-Oxidized Bacterial Cellulose. Advanced Functional Materials, 25(23), 3560-3570. https://doi.org/10.1002/adfm.201500673

Kuczynska, A., Uygun, A., Kaim, A., Wilczura-Wachnik, H., Yavuz, A. G., \& Aldissi, M. (2010). Effects of surfactants on the characteristics and biosensing properties of polyaniline. Polymer International, 59(12), 1650-1659. https://doi.org/10.1002/pi.2898

L. Y. Ji, Kang, E. T., Neoh, K. G., \& Tan, K. L. (1999). Surface Modification of Poly(tetrafluoroethylene) Film by Consecutive Graft Copolymerization with 4-Vinylaniline and Aniline. Macromolecules, 32(24), 8183-8188. https://doi.org/10.1021/MA990646F

Langer, J. J., Filipiak, M., Ke,cińska, J., Jasnowska, J., Włodarczak, J., \& Buładowski, B. (2004). Polyaniline biosensor for choline determination. Surface Science, 573(1), 140-145. https://doi.org/10.1016/J.SUSC.2004.05.140

Lee, B.-H., Kim, H.-J., \& Yang, H.-S. (2012). Polymerization of aniline on bacterial cellulose and characterization of bacterial cellulose/polyaniline nanocomposite films. Current Applied Physics, 12(1), 75-80. https://doi.org/10.1016/j.cap.2011.04.045

Lee, H.-J., Chung, T.-J., Kwon, H.-J., Kim, H.-J., \& Tze, W. T. Y. (2012). Fabrication and evaluation of bacterial cellulose-polyaniline composites by interfacial polymerization. Cellulose, 19(4), 1251-1258. https://doi.org/10.1007/s10570-012-9705-5

Li, D., \& Kaner, R. B. (2007). How nucleation affects the aggregation of nanoparticles. Journal of Materials Chemistry, 17(22), 2279. https://doi.org/10.1039/b700699c 
Li, J., Fang, L., Tait, W. R., Sun, L., Zhao, L., \& Qian, L. (2017). Preparation of conductive composite hydrogels from carboxymethyl cellulose and polyaniline with a nontoxic crosslinking agent. RSC Advances, 7(86), 54823-54828. https://doi.org/10.1039/C7RA10788A

Li, Y., \& Li, Y. (2015). Conducting Polymers. In Y. Li (Ed.), Organic Optoelectronic Materials (p. 392). Beijing: Springer, Cham. https://doi.org/10.1007/978-3-319-16862-3_2

Liu, D. Y., Sui, G. X., \& Bhattacharyya, D. (2014). Synthesis and characterisation of nanocellulose-based polyaniline conducting films. Composites Science and Technology, 99, 31-36. https://doi.org/10.1016/J.COMPSCITECH.2014.05.001

Liu, P.-S., Chen, Q., Liu, X., Yuan, B., Wu, S.-S., Shen, J., \& Lin, S.-C. (2009). Grafting of Zwitterion from Cellulose Membranes via ATRP for Improving Blood Compatibility. Biomacromolecules, 10(10), 2809-2816. https://doi.org/10.1021/bm9006503

Lizundia, E., Meaurio, E., \& Vilas, J. L. (2016). Grafting of Cellulose Nanocrystals. Multifunctional Polymeric Nanocomposites Based on Cellulosic Reinforcements, 61-113. https://doi.org/10.1016/B978-0-323-44248-0.00003-1

Loh, Q. L., \& Choong, C. (2013). Three-dimensional scaffolds for tissue engineering applications: role of porosity and pore size. Tissue Engineering. Part B, Reviews, 19(6), 485-502. https://doi.org/10.1089/ten.TEB.2012.0437

Mahalakshmi, B., \& Vedhi, C. (2014). Synthesis and Characterization of Perfluorooctanoic Acid Anionic Surfactant Doped Nanosize Polyaniline. Open Journal of Synthesis Theory and Applications, 3(3), 57-68. https://doi.org/10.4236/ojsta.2014.34008

McCandless, D. W. (1997). Fundamental neuroscience. Metabolic Brain Disease, 12(1), 93-93. https://doi.org/10.1007/BF02676357 
Mirmohseni, A., \& Oladegaragoze, A. (2000). Anti-corrosive properties of polyaniline coating on iron. Synthetic Metals, 114(2), 105-108. https://doi.org/10.1016/S0379-6779(99)00298-2

Müller, D., Mandelli, J. S., Marins, J. A., Soares, B. G., Porto, L. M., Rambo, C. R., \& Barra, G. M. O. (2012). Electrically conducting nanocomposites: preparation and properties of polyaniline (PAni)-coated bacterial cellulose nanofibers (BC). Cellulose, 19(5), 1645-1654. https://doi.org/10.1007/s10570-012-9754-9

Persin, Z., Mozetic, M., Vesel, A., Maver, T., Maver, U., \& Stana, K. (2013). Plasma Induced Hydrophilic Cellulose Wound Dressing. In Cellulose - Medical, Pharmaceutical and Electronic Applications. InTech. https://doi.org/10.5772/55867

Peters, M. J., Stinstra, J. G., \& Leveles, I. (2004). The Electrical Conductivity of Living Tissue: A Parameter in the Bioelectrical Inverse Problem (pp. 281-319). https://doi.org/10.1007/978-0-387-49963-5_9

R. Rebelo, A., Archer, A. J., Chen, X., Liu, C., Yang, G., \& Liu, Y. (2018). Dehydration of bacterial cellulose and the water content effects on its viscoelastic and electrochemical properties. Science and Technology of Advanced Materials, 19(1), 203-211. https://doi.org/10.1080/14686996.2018.1430981

Rotin, D., Robinson, B., \& Tannock, I. F. (1986). Influence of hypoxia and an acidic environment on the metabolism and viability of cultured cells: potential implications for cell death in tumors. Cancer Research, 46(6), 2821-2826. Retrieved from http://www.ncbi.nlm.nih.gov/pubmed/3698008

Ruan, C., Zhu, Y., Zhou, X., Abidi, N., Hu, Y., \& Catchmark, J. M. (2016). Effect of cellulose crystallinity on bacterial cellulose assembly. Cellulose, 23(6), 3417-3427.

https://doi.org/10.1007/s10570-016-1065-0 
Sapurina, I., \& Stejskal, J. (2008). The mechanism of the oxidative polymerization of aniline and the formation of supramolecular polyaniline structures. Polymer International, 57(12), 1295-1325. https://doi.org/10.1002/pi.2476

Sapurina, I. Y., \& Shishov, M. A. (2012). Oxidative Polymerization of Aniline: Molecular Synthesis of Polyaniline and the Formation of Supramolecular Structures. In New Polymers for Special Applications (pp. 251-312). InTech. https://doi.org/10.5772/48758

Shah, N., Ul-Islam, M., Khattak, W. A., \& Park, J. K. (2013). Overview of bacterial cellulose composites: A multipurpose advanced material. Carbohydrate Polymers, 98(2), 1585-1598. https://doi.org/10.1016/J.CARBPOL.2013.08.018

Shi, Z., Li, Y., Chen, X., Han, H., \& Yang, G. (2014). Double network bacterial cellulose hydrogel to build a biology-device interface. Nanoscale, 6(2), 970-977. https://doi.org/10.1039/c3nr05214a

Shi, Z., Zang, S., Jiang, F., Huang, L., Lu, D., Ma, Y., \& Yang, G. (2012). In situ nano-assembly of bacterial cellulose-polyaniline composites. RSC Advances, 2(3), 1040. https://doi.org/10.1039/c1ra00719j

Skotheim, T. A., \& Reynolds, J. R. (2007). Handbook of conducting polymers. (T. A. Skotheim \& J. Reynolds, Eds.) (3rd ed.). New York: CRC.

Smela, E., Lu, W., \& Mattes, B. R. (2005). Polyaniline actuators: Part 1. PANI(AMPS) in HCl. Synthetic Metals, 151(1), 25-42. https://doi.org/10.1016/J.SYNTHMET.2005.03.009

Soto-Oviedo, M. A., Araújo, O. A., Faez, R., Rezende, M. C., \& De Paoli, M.-A. (2006). Antistatic coating and electromagnetic shielding properties of a hybrid material based on polyaniline/organoclay nanocomposite and EPDM rubber. Synthetic Metals, 156(18-20), 1249-1255. https://doi.org/10.1016/J.SYNTHMET.2006.09.003 
Spearman, B. S., Desai, V. H., Mobini, S., McDermott, M. D., Graham, J. B., Otto, K. J., ... Schmidt, C. E. (2018). Tissue-Engineered Peripheral Nerve Interfaces. Advanced Functional Materials, 28(12), 1701713. https://doi.org/10.1002/adfm.201701713

Stejskal, J., Sapurina, I., \& Trchová, M. (2010). Polyaniline nanostructures and the role of aniline oligomers in their formation. Progress in Polymer Science, 35(12), 1420-1481. https://doi.org/10.1016/j.progpolymsci.2010.07.006

Tanwar, S., \& Ho, J. (2015). Green Synthesis of Novel Polyaniline Nanofibers: Application in pH Sensing. Molecules, 20(10), 18585-18596. https://doi.org/10.3390/molecules201018585

Tian, Z., Yu, H., Wang, L., Saleem, M., Ren, F., Ren, P., ... Huang, L. (2014). Recent progress in the preparation of polyaniline nanostructures and their applications in anticorrosive coatings. RSC Advances, 4(54), 28195. https://doi.org/10.1039/c4ra03146f

Tong, Z., Yang, Y., Wang, J., Zhao, J., Su, B.-L., \& Li, Y. (2014). Layered polyaniline/graphene film from sandwich-structured polyaniline/graphene/polyaniline nanosheets for highperformance pseudosupercapacitors. J. Mater. Chem. A, 2(13), 4642-4651. https://doi.org/10.1039/C3TA14671E

Ul-Islam, M., Khattak, W. A., Ullah, M. W., Khan, S., \& Park, J. K. (2014). Synthesis of regenerated bacterial cellulose-zinc oxide nanocomposite films for biomedical applications. Cellulose, 21(1), 433-447. https://doi.org/10.1007/s10570-013-0109-y

Valentová, H., \& Stejskal, J. (2010). Mechanical properties of polyaniline. Synthetic Metals, 160(7-8), 832-834. https://doi.org/10.1016/J.SYNTHMET.2010.01.007

Wang, F., Jeon, J.-H., Park, S., Kee, C.-D., Kim, S.-J., \& Oh, I.-K. (2016). A soft biomolecule actuator based on a highly functionalized bacterial cellulose nano-fiber network with carboxylic acid groups. Soft Matter, 12(1), 246-254. https://doi.org/10.1039/C5SM00707K 
Wang, H., Fu, Y., Wang, Z., Shao, Z., \& Qin, M. (2017). REGIOSELECTIVITY IN THE ACYLATION OF CELLULOSE WITH 2-BROMOISOBUTYRYL BROMIDE UNDER HOMOGENEOUS CONDITIONS. CELLULOSE CHEMISTRY AND TECHNOLOGY Cellulose Chem. Technol, 51(12), 11-21. Retrieved from http://www.cellulosechemtechnol.ro/pdf/CCT1-2(2017)/p.11-21.pdf

Wang, H., Zhu, E., Yang, J., Zhou, P., Sun, D., \& Tang, W. (2012). Bacterial Cellulose Nanofiber-Supported Polyaniline Nanocomposites with Flake-Shaped Morphology as Supercapacitor Electrodes. The Journal of Physical Chemistry C, 116(24), 13013-13019. https://doi.org/10.1021/jp301099r

Wu, Z.-Y., Li, C., Liang, H.-W., Chen, J.-F., \& Yu, S.-H. (2013). Ultralight, Flexible, and FireResistant Carbon Nanofiber Aerogels from Bacterial Cellulose. Angewandte Chemie, 125(10), 2997-3001. https://doi.org/10.1002/ange.201209676

Xie, H.-Q., Ma, Y.-M., \& Feng, D.-S. (2000). Preparation of organosoluble conductive polyaniline via precipitation polymerization and study of its conductivity. European Polymer Journal, 36(10), 2201-2206. https://doi.org/10.1016/S0014-3057(99)00283-9

Xing, S., Zhao, C., Jing, S., \& Wang, Z. (2006). Morphology and conductivity of polyaniline nanofibers prepared by 'seeding' polymerization. Polymer, 47(7), 2305-2313. https://doi.org/10.1016/J.POLYMER.2006.02.008

Yan, H., Sada, N., \& Toshima, N. (2002). Thermal transporting properties of electrically conductive polyaniline films as organic thermoelectric materials. Journal of Thermal Analysis and Calorimetry, 69(3), 881-887. https://doi.org/10.1023/A:1020612123826

Yu Sapurina, I., \& Stejskal, J. (2012). Oxidation of Aniline with Strong and Weak Oxidants. ISSN Russian Journal of General Chemistry, 82(2), 1070-3632. 
https://doi.org/10.1134/S1070363212020168

Yuan, S., Tang, S., Lv, L., Liang, B., Choong, C., \& Pehkonen, S. O. (2012). Poly(4vinylaniline) - Polyaniline Bilayer-Modified Stainless Steels for the Mitigation of Biocorrosion by Sulfate-Reducing Bacteria (SRB) in Seawater. Industrial \& Engineering Chemistry Research, 51(45), 14738-14751. https://doi.org/10.1021/ie302303x 